\title{
Prevalence of Oral Lesions in Patients with Inflammatory Bowel Disease
}

\section{THESIS}

Presented in Partial Fulfillment of the Requirements for the Degree Master of Science in the Graduate School of The Ohio State University

\author{
By \\ Amber Kiyani \\ Graduate Program in Dentistry
}

The Ohio State University

2014

Master's Examination Committee:

Carl M Allen (Co-Advisor)

Kristin K McNamara (Co-Advisor)

F Michael Beck

Razvan Arsenescu 
Copyright by

Amber Kiyani

2014 


\begin{abstract}

\section{Introduction:}

Inflammatory bowel disease is a group of idiopathic conditions characterized by chronic inflammation of the gastrointestinal tract, with Crohn's disease and ulcerative colitis being two common forms of this process. Extraintestinal manifestations of inflammatory bowel disease can be seen repeatedly in over $50 \%$ of patients, and can involve the skin, oral cavity, eyes, joints and the biliary tract.

Oral lesions specific to Crohn's disease and ulcerative colitis often have very characteristic appearances. Some non-specific processes such as aphthous ulceration and candidiasis have also been linked to this condition. Despite detailed documentation of the presence and the nature of oral lesions in patients with inflammatory bowel disease, limited data is available regarding the prevalence. The objective of this study was to estimate the frequency of oral changes associated with inflammatory bowel disease in the U.S population in comparison to age- and sex- matched healthy controls.
\end{abstract}

\title{
Methodology:
}

One hundred patients with a prior diagnosis of either Crohn's disease or ulcerative colitis underwent periodic comprehensive oral examinations at the Wexner Medical Center gastroenterology clinic. Any abnormal oral mucosal changes noted during the exam were documented. A control population underwent a similar exam and documentation in the new patient screening clinic of The Ohio State University, College of Dentistry. 


\section{Results:}

Out of 100 patients in the inflammatory bowel disease group, three were unavailable for follow-up. No lesions specific to either Crohn's disease or ulcerative colitis were noted in the remaining ninety-seven patients over the 12-month period. Two patients presented with candidiasis, 2 with aphthous ulcers and 2 with herpetic lesions. One patient in the control group also presented with aphthous ulcers.

\section{Conclusion:}

Based on these findings, the prevalence of oral lesions in this patient population with inflammatory bowel disease can be estimated to be less than $1 \%$. 


\section{Dedication}

This document is dedicated to Ammi and Abu,

for their constant and unselfish love, kindness and support. 


\section{Acknowledgments}

I would like to express my deepest appreciation to my co-advisors, Dr. Carl Allen and Dr. Kristin McNamara for their mentorship and guidance through the course of this project. I am also grateful to Dr. Michael Beck for patiently trouble-shooting all my statistical issues, Dr. Razvan Arsenescu for generously providing access to his patients, and Dr. Susan Mallery for her constant encouragement.

I also thank Dr. John Kalmar, Drs. Neetha Santosh, and Wendi O’Neill, Mary Marin, Mary Lloyd, Sherrie Tavtigian, Monica Beatty, Rebecca Crader and Rebecca Ray for their contributions and support. 


\section{Vita}

2009

BDS, Riphah International University,

Islamabad, Pakistan

$2011-2014$

Graduate Oral and Maxillofacial Pathology

Residency, The Ohio State University, Columbus, Ohio

\section{Fields of Study}

Major Field: Dentistry 


\section{Table of Contents}

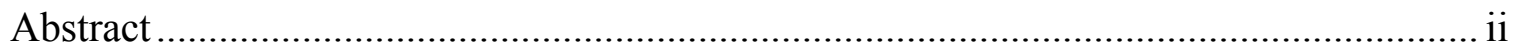

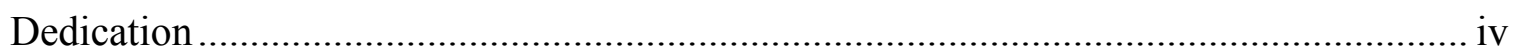

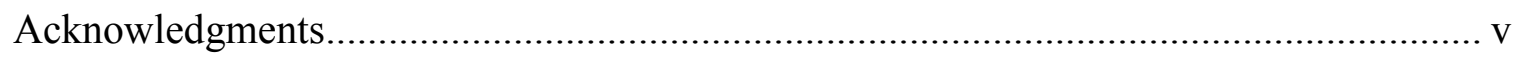

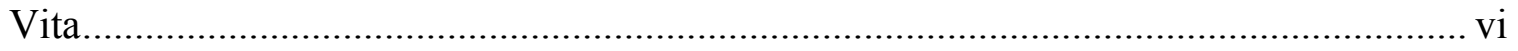

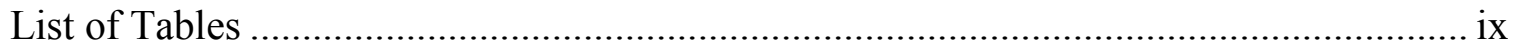

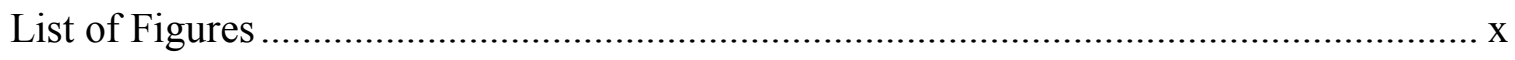

Chapter 1: Introduction and Statement of Problem .................................................. 1

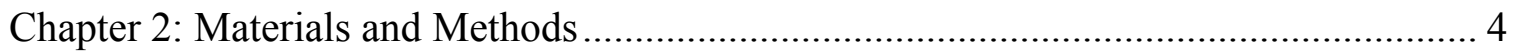

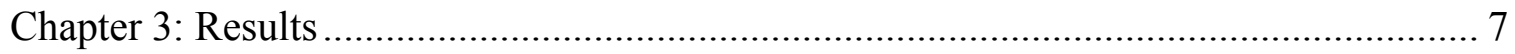

Chapter 4: Discussion, Avenues for Future Research and Conclusion ........................... 8

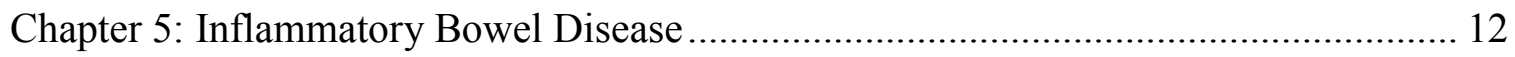

Chapter 6: Pathogenesis.................................................. 15

Chapter 7: Extraintestinal Manifestations of Inflammatory Bowel Disease ................... 19

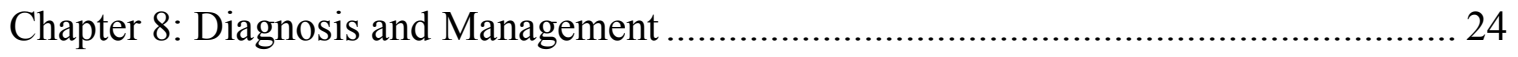

Chapter 9: Oral Manifestations of Inflammatory Bowel Disease ................................ 43

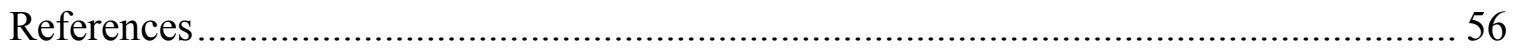


Appendix A: Raw Data Tables .

Appendix B: Human Subject Research Forms.................................68

Appendix C: Data Collection Sheets........................................82 


\section{List of Tables}

Table 1: Frequency of specific oral lesions in patients with IBD and normal controls....61

Table 2: Race and gender distribution of IBD patients and normal controls...........67

Table 3: Age distribution by decade in IBD patients and normal controls..............67 


\section{List of Figures}

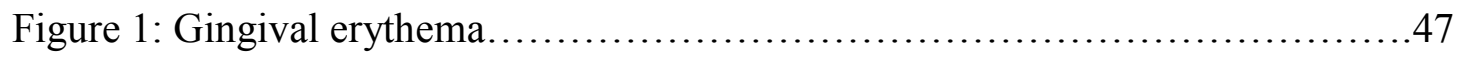

Figure 2: Lip swelling ...............................................47

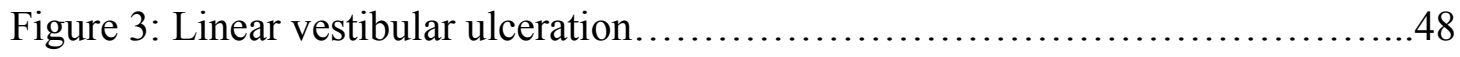

Figure 4: Mucosal tags................................................48

Figure 5: Pyostomatitis vegetans.......................................49

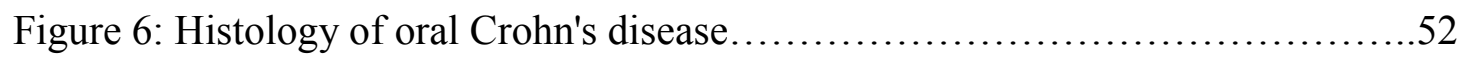

Figure 7: Histology of pyostomatitis vegetan...............................53 


\section{Chapter 1: Introduction and Statement of Problem}

Inflammatory bowel disease is a group of idiopathic conditions characterized by chronic inflammation of the gastrointestinal tract. Crohn's disease and ulcerative colitis are the two most common forms of this process (1). About 1.4 million people in the United States are affected by these conditions. The prevalence of Crohn's disease appears to be slightly higher than ulcerative colitis. An equal sex distribution is seen between the two processes (2). Extraintestinal involvement with inflammatory bowel disease has been reported in over $50 \%$ of patients. Skin, oral mucosa, eyes, and the musculoskeletal system are most frequently involved (3).

Oral involvement with inflammatory bowel disease was first reported by two separate individuals in $1969(4,5)$. It is seen more commonly in association with Crohn's disease than ulcerative colitis, and children appear to have a higher risk of oral involvement $(6,7)$. Estimates of adult involvement range between 0.5 to $9 \%(8,9)$. Oral lesions associated with inflammatory bowel disease have been described as linear vestibular ulceration, mucosal swelling, gingivostomatitis, cobblestoning, and pyostomatitis vegetans. Linear vestibular ulceration is found along the length of the buccal vestibule. Mandibular mucosa appears to be more commonly involved. The lesions result in significant discomfort and pain. Adjacent to the ulceration, hyperplastic folds of mucosa, known as mucosal tags may also be identified. Mucosal swelling presents as non-tender, firm enlargement of the lips and buccal mucosa. Lip swelling is 
occasionally accompanied by a chronic fissure. Esthetic concerns often force the patient to seek treatment. Gingivostomatitis is characterized by the presence of multiple erythematous plaques that are unresponsive to oral hygiene measures. Cobblestoning presents as asymptomatic, diffuse, multinodular swelling of the oral mucosa. Sites of involvement include the buccal and labial mucosa, and rarely, gingiva. Pyostomatitis vegetans is seen more frequently in association with ulcerative colitis. It presents as painful, yellow, linear pustules that evolve into characteristic "snail track" ulcers. Any oral site may be involved $(7,10-12)$.

Several studies have also linked non-specific oral processes with inflammatory bowel disease. Aphthous ulceration, candidiasis and erythema migrans are frequently included in this category $(10,13,14)$.

The clinical course of oral manifestations of inflammatory bowel disease is variable, difficult to predict, and appears to be independent of intestinal disease activity. In some patients, oral lesions may precede intestinal disease by several years, while in others, oral manifestations may occur after the resolution of intestinal inflammation. In most cases, the lesions are resistant to systemic therapy for intestinal disease. They can persist for time periods ranging between weeks to several years (15-18).

With a prior diagnosis of inflammatory bowel disease, the diagnosis of oral involvement should be relatively easy to make clinically. Biopsy of the oral lesions can usually help in confirming the diagnosis. Granulomatous inflammation consistent with Crohn's disease can be identified in up to $67 \%$ of biopsy specimens from linear vestibular ulceration, 
mucosal tags, mucogingivitis and cobblestoning (6). Pyostomatitis vegetans is characterized by the presence of eosinophilic abscesses in the epithelium (12).

\section{Objective:}

The primary objective of this study was to analyze the prevalence of oral lesions in patients with inflammatory bowel disease in comparison to an age and sex matched healthy control population. All non-specific oral processes were excluded from the estimate.

\section{Rationale:}

A rapid decline in the number of studies estimating the prevalence of oral lesions associated with inflammatory bowel disease is noted in the 1990s. This makes the majority of the literature available on the subject at least two decades old. Most studies originate from European countries, namely Italy, Great Britain and France $(8,9,14)$. The study designs are either prospective or retrospective, and in most cases fail to include age- and sex-matched control populations. The investigators are primarily gastroenterologists and rarely, dentists. The reliability of their skills to evaluate and diagnose oral disease may be limited. The results from these investigations are variable and include non-specific oral processes, such as aphthous ulceration, geographic tongue and candidiasis in their estimates. 


\section{Chapter 2: Materials and Methods}

This project was approved by The Ohio State University Institutional Board Review (protocol number 2012H034).

The patient population was divided into two separate groups;

- Group I: Patients with inflammatory bowel disease

- Group II: Normal controls

\section{Group I:}

Initial Evaluation:

One hundred consecutive, consenting adult patients with a prior diagnosis of either Crohn's disease or ulcerative colitis were recruited through the clinic at the Wexner Medical Center, Department of Gastroenterology and Hepatology. Following consent, medical history documenting all medications currently under use was obtained and a comprehensive oral examination involving visual inspection of all mucosal surfaces was performed using a dental mirror. Recording of all oral anomalies was made on the data collection sheet along with the patient's demographics, medical diagnosis and the date of the exam. The date for return appointments was also noted.

Follow-up Evaluation:

Comprehensive oral examination was repeated at follow-up visits scheduled by the Wexner Medical Center, Department of Gastroenterology and Hepatology. The re- 
evaluation involved re-examination of the oral mucosa with documentation of any mucosal alterations on the data collection sheet along with the date of the exam. Each patient was seen a minimum of two times during the twelve-month period.

\section{Group II:}

One hundred adult patients presenting to the College of Dentistry new patient screening clinics for routine dental problems were recruited as healthy controls. Attempts were made to ensure that the recruited population was age and sex matched with the patient population in Group I. Following consent, their medical history was reviewed to ensure that there was no history of any gastrointestinal disease and a comprehensive oral exam was performed. The patient's demographics, date of the exam and any mucosal changes were noted on data collection sheets. This completed the participation for Group II in the study.

\section{Subject Confidentiality:}

No personal identifiable information was recorded for Group II. Each study subject in the control population was given a coded identity for data entry. For follow-up reasons, the names of the patients in Group I were retained until their study participation was complete. Following completion, all of their personal identifiable information was shredded and only their code number was associated with the collected data.

The data collection sheets were stored in a file cabinet in a locked room with limited access capabilities. The study roster was password protected and stored on a 
password protected computer, in the Division of Oral and Maxillofacial Pathology and Radiology, College of Dentistry. 


\section{Chapter 3: Results}

Of 100 patients with inflammatory bowel disease enrolled in the study, 3 were unavailable for follow-up. The 54 women and 46 men ranged in age between 18 and 76 with an average age of 38.6 years. Twenty patients had a diagnosis of ulcerative colitis, while 77 had Crohn's disease. Ninety-one percent of the patients were Caucasian, 7\% African-American, and 2\% Asian. Time since initial diagnosis for patients was between 2 and 35 years. All patients were taking medications at the time, including 6mercaptopurines, anti-tumor necrosis factor (anti-TNF) agents, azathioprine and corticosteroids. The patient populations in the inflammatory bowel disease groups and the healthy control group were appropriately age-, race- and sex-matched. None of the patients in the inflammatory bowel disease group exhibited oral lesions specific to inflammatory bowel disease. However, only one patient reported a history of recurrent oral lesions consistent with linear vestibular ulcers. Two patients presented with lesions consistent with aphthous ulceration, both of which exhibited complete resolution of lesions on follow-up evaluation. Central papillary atrophy, angular cheilitis and cultures positive for candidiasis were identified in two patients. In addition, herpes labialis was

noted in two patients. Aphthous ulceration was identified in one patient in the control population. 


\section{Chapter 4: Discussion, Avenues for Future Research and Conclusion}

\section{Discussion:}

This study estimates the prevalence of oral manifestations in patients with inflammatory bowel disease to be less than $1 \%$. These results differ significantly from Asquith's investigation of 200 patients at the East Birmingham Hospital in 1975 that calculated the prevalence of oral lesions in patients with Crohn's disease to be $9 \%$, and in patients with ulcerative colitis $2 \%$. While the 1975 study was appropriately controlled and performed by a group of oral pathologists, it did include benign migratory glossitis as an oral manifestation of inflammatory bowel disease (9). The discrepancy between our results and those of the British could be due to geographical differences in the poulations. Our findings are consistent with the study by Lisciandrano et al, published in 1996. The group examined 198 patients with inflammatory bowel disease and was unable to detect any specific oral lesions. The group noted a higher prevalence of oral candidiasis in patients with Crohn's disease than those with ulcerative colitis or normal controls (14). Similarly, a French group of researchers followed 1805 adult patients with Crohn's disease from 1975 to 1977 , and they found only $9(0.5 \%)$ patients with specific oral

lesions. Their findings were presented only as an abstract for the Academy of Gastroenterology (8).

Aphthous ulceration is considered one of the most common presentations of inflammatory bowel disease. It is estimated that 20 to $30 \%$ of patients with Crohn's 
disease and $10 \%$ of patients with ulcerative colitis present with aphthous ulceration (19). The prevalence of this type of ulceration in the general population is estimated to be between 5 to $25 \%(20)$. This indicates that the prevalence of recurrent aphthous ulceration in patients with inflammatory bowel disease and the normal population is roughly similar. While we identified two patients with aphthous ulceration in our study population, we also noted active lesions in one patient in our control group.

A higher prevalence of oral candidiasis and herpetic infections was noted in our study population in comparison to healthy controls. Oral candidiasis presented as central papillary atrophy and angular cheilitis. Evidence of infection was confirmed by performing a candidal culture. Herpetic lesions in two patients were identified on the upper lip. All four patients were taking either anti-TNF agents or immunomodulators for the treatment of their bowel disease. We believe that these infectious processes are not linked to the intestinal disease activity, and may have occurred secondary to the use of immunosuppressive medications. Changes in the immune status due to drug use predisposed these individuals to develop oral candidiasis and recurrent herpes labialis (21).

Only one patient in our study population gave a detailed history of recurrent ulceration along the length of the mandibular vestibule that could be consistent with linear vestibular ulceration. However, no lesions were seen on the initial or follow-up visits. The number of years since initial diagnosis of inflammatory bowel disease in our patients varied between 2 and 35 years. Although we tried to obtain a thorough history of 
oral involvement, we cannot rule out the possibility that patients were unable to recall events from several decades ago.

\section{Avenues for Future Research:}

Oral lesions specific to inflammatory bowel disease appear to be more prevalent in pediatric patients. Estimates for oral involvement with Crohn's disease range between 20 to $41.7 \%(22,23)$. The prevalence of oral lesions reported in association with ulcerative colitis is less than 5\% (22). Since our study did not include a pediatric population, it would be interesting to perform a similar study in a younger population from the United States.

The patients recruited for this study had a prior diagnosis of either Crohn's disease or ulcerative colitis and had been on medications for several years. Since $30 \%$ of oral lesions associated with Crohn's disease reportedly precede intestinal involvement, studying a naïve population might yield different results (7).

Our study followed ninety seven patients with inflammatory bowel disease over a period of 12 months. Increasing the sample size and the follow-up period will be useful in making definitive assessments about prevalence of oral lesions in patients with inflammatory bowel disease.

\section{Conclusion:}

Inflammatory bowel disease is a chronic inflammatory process of the gastrointestinal tract that reportedly may present with extraintestinal involvement in a 
significant number of patients. Presence of oral lesions has been documented by several reports and studies. Linear vestibular ulceration, mucosal swelling, mucosal tags, gingivostomatitis, cobblestoning and pyostomatitis vegetans are considered characteristic oral presentations of the disease. We attempted to estimate the prevalence of these lesions in patients with inflammatory bowel disease. Our results suggest that oral manifestations are rare and may be seen in less than $1 \%$ of the affected population during a 12 -month period. 


\section{Chapter 5: Inflammatory Bowel Disease}

A literature search through PubMed was performed for inflammatory bowel disease, Crohn's disease, ulcerative colitis, clinical features, pathogenesis, extraintestinal manifestations, diagnosis and treatment. The search was not limited by a date range.

\section{INFLAMMATORY BOWEL DISEASE:}

Inflammatory bowel disease is a group of idiopathic conditions characterized by chronic inflammation of the gastrointestinal tract $(1,24)$. The disease has a long and protracted course with periods of active disease and remission(25). Crohn's disease and

ulcerative colitis are the two most common forms of the process $(1,26)$. Both conditions have unique clinical, radiographic, endoscopic and microscopic presentations $(1,27)$. They will each be discussed in more detail in the following paragraphs.

\subsection{Epidemiology:}

About 1.4 million people are estimated to suffer from inflammatory bowel disease in the United States. The prevalence of Crohn's disease is estimated at 119 cases per 100,000 persons, and for ulcerative colitis at 71 cases per 100,000 individuals. The majority of people afflicted with these conditions are Caucasians, followed by African Americans. A 1:1 female-to-male ratio is seen in patients with Crohn's disease while ulcerative colitis shows a female predilection(2). 


\subsection{Crohn's Disease:}

Crohn's disease is a type of inflammatory bowel disease characterized by granulomatous inflammation that may affect any site of the gastrointestinal tract, from the mouth to the anus $(28,29)$. The most common site of involvement is the terminal ileum (47\%), followed by the colon (28\%), both large and small bowel $(21 \%)$ and the upper gastrointestinal tract (3\%) (30).

\section{Pathogenesis:}

See Chapter 6.

\section{Clinical Presentation:}

The disease onset has a bimodal distribution with the majority of cases being diagnosed between the ages of 15-30 years and 60-80 years (29). The symptoms of Crohn's disease depend on the location and severity of the condition. Diarrhea, weight loss and abdominal cramping are some of the common presenting symptoms (31). Fever, malaise, anorexia, melena and rectal bleeding may also be seen (32). Vomiting may occur with or without evidence of overt obstruction (33). About 13\% of patients with Crohn's disease present with fistulas and abscesses, and 17\% with stricture formation. Patients with a more protracted disease course are at a higher risk for developing these complications(27). 


\subsection{Ulcerative Colitis:}

Ulcerative colitis is a non-infectious chronic inflammatory process that involves the colon and the rectum (34). The inflammation initially involves the rectum and extends proximally into the colon (34).

\section{Pathogenesis:}

See Chapter 6.

\section{Clinical Presentation:}

The onset of disease is usually in early adulthood. A higher prevalence of the disease is noted in the westernized world. Symptoms depend on the extent and severity of involvement. For most patients variation in the severity of symptoms is seen over a period of time. Rectal bleeding, urgency and tenesmus are frequent presenting complaints (35). Bloody diarrhea, abdominal pain, fever, weight loss and malaise may also be reported. Long term involvement may be characterized by malnutrition, weight loss and anemia (36). Extraintestinal manifestations of the disease reportedly may be noted in up to $30 \%$ of patients (35). 


\section{Chapter 6: Pathogenesis of Inflammatory Bowel Disease}

Inflammatory bowel disease is classified in the category of idiopathic diseases. While the exact etiology of this disease remains unknown, several theories attempt to explain the process (26).

Crohn's disease is primarily an abnormal cell-mediated immune response that is initiated by interleukin 12 (IL-12). Elevated levels of IL-12 stimulate the production of gamma-interferon $(\gamma$-IFN) and tumor necrosis factor-alpha (TNF- $\alpha)$. Release of these cytokines activates the macrophages and B-cells to elicit a response against the gastrointestinal mucosa $(26,37)$.

In ulcerative colitis, the immune attack is elicited by a series of cytokines produced during the inflammatory cascade. The events lead to the activation of a humoral immune response and production of non-cytolytic antibodies against colonic mucosa by B-cells. $(26,36,37)$.

Recent studies have described the role of IL-23/Th-17 pathway in the pathogenesis of chronic inflammatory diseases. Activation of IL-23 by IL-12 results in the formation of unique helper $\mathrm{T}$ cells, Th17. These cells are responsible for mediating inflammation and autoimmune responses. Current research is focused on investigating this pathway as a potential therapeutic target $(38,39)$. 


\section{Environmental Factors:}

Immune-mediated diseases exhibit a higher prevalence in developed countries with the highest rates being reported in Northern Europe and North America (40). This is attributed to improved sanitation, consumption of sterile and non-fermented food and use of vaccines. Decreased exposure to pathogens is thought to lead the development of an overactive immune system $(26,27)$.

Smoking is considered a risk factor for Crohn's disase. Women who smoke tend to have a higher risk than men. Interestingly, smokers have a lower risk for ulcerative colitis when compared to non-smokers $(24,40)$. Some studies have attributed a higher prevalence of inflammatory bowel disease to declining rates of appendectomy. The procedure appears to protect against ulcerative colitis. The association between Crohn's disease and appendectomy is less clear (40).

The role of breastfeeding, psychological stress, a high protein diet, childhood infections and use of non-corticosteroidal anti-inflammatory drugs in the pathogenesis of inflammatory bowel disease is equivocal. Evidence supporting these premises is limited and controversial $(34,40)$.

\section{Genetic Factors:}

\section{Ethnicity:}

The Jewish population is at a much higher risk for developing inflammatory bowel disease. The risk is two to four times higher when compared to other populations. 
Certain ethnicities, such as African Americans and Asians, exhibit much lower rates of involvement with this process(36).

Family History:

People with a positive family history of Crohn's disease or ulcerative colitis are 2 to 13 times more likely to develop either of the processes in comparison to healthy controls. Concordance rates for Crohn's disease are between 20 and 50\% in monozygotic twins, while those for dizygotic twins are below $10 \%$. These results support the notion of genetic predisposition (36).

Inflammatory Bowel Disease Loci:

Currently almost 99 genetic loci have been linked to inflammatory bowel disease. Alterations in nucleotide-binding oligomerization domain-containing protein 2 (NOD2) on chromosome 16 have been identified in $10-15 \%$ of patients with Crohn's disease. Mutated NOD2 results in an exaggerated immune response against enteric microorganisms. This leads to destruction of the intestinal mucosa and the onset of symptoms of Crohn's disease $(36,41)$.

\section{Immunological Factors:}

An overactive immune response that is directed against the normal flora of the bowel is considered to be an important component in the pathogenesis of inflammatory bowel disease. This concept is supported by the following findings: increased bacterial colonization is noted in areas of inflammation; rerouting the fecal stream will usually eliminate the inflammation; and patients with inflammatory bowel disease tend to harbor 
large bacterial populations (26). Studies have also shown a defective barrier mechanism of the colonic mucosa in affected individuals (34).

\section{Microbial Factors:}

Alterations of gut flora following antibiotic therapy have been implicated as a potential etiology for inflammatory bowel disease (40). The role of microbial agents in the pathogenesis and development of this process is controversial. Reports link Mycobacterium paratuberculosis, Pseudomonas and Listeria with Crohn's disease. Similarly, Bacillus species, E coli and Fusobacterium have been associated with ulcerative colitis (36).

\section{Toll-like Receptors and NOD Signalling:}

Toll-like receptors are proteins that play an important role in intestinal immunity. These proteins enable the immune system to distinguish between pathogenic organisms and the normal flora. If this ability is lost, the body's immune response will react against the intestinal flora, leading to chronic inflammatory conditions such as inflammatory bowel disease. Toll receptor proteins appear to be dysregulated in patients with inflammatory bowel disease.

Nucleotide-binding-oligomerization-domain (NOD) proteins are located intracellularly and have roles similar to toll-like receptor proteins. Alterations in the protein architecture can predispose an individual to an overactive immune response (26). 


\section{Chapter 7: Extraintestinal Manifestations of Inflammatory Bowel Disease}

Extraintestinal manifestations of inflammatory bowel disease may be seen in approximately $50 \%$ of the patients. Skin, oral mucosa, eyes, joints, biliary tract and lungs are frequently involved (33). Patients with perianal Crohn's disease have a higher likelihood of developing extraintestinal manifestations of the condition (3).

Although the exact mechanism of extraintestinal involvement is currently unknown, "genetic susceptibility, antigenic display of autoantigen, aberrant self-recognition and immunopathogenetic autoantibodies" are implicated in the pathogenesis of the disease (3).

\section{Skin:}

Cutaneous lesions associated with inflammatory bowel disease are seen in about $34 \%$ of patients and can present as erythema nodosum, pyoderma gangrenosum, Sweet's syndrome or psoriasis. $(42,43)$.

Erythema nodosum can be seen in up to $15 \%$ of patients with Crohn's disease. It presents as tender, elevated, red plaques that can vary in size between 1 and $5 \mathrm{~cm}$. Lower extremities are more commonly involved. The diagnosis is based on the clinical findings and the condition resolves once the underlying bowel disease is controlled $(19,42,43)$.

Pyoderma gangrenosum is characterized by multiple, red pustules that enlarge rapidly and evolve into large and painful ulcers. Involvement of the extremities and 
periorificial skin is typically seen. The condition is resistant to medications used for treatment of intestinal disease. The lesions need to be treated independently with topical corticosteroids or systemic therapy $(42,43)$.

Sweet's syndrome is an acute febrile neutrophilic dermatosis characterized by tender, red papules on the upper extremities. The diagnosis is confirmed by biopsy and the lesions are responsive to treatment administered for intestinal inflammation (43).

Psoriasis is a chronic inflammatory process that is seen more commonly in association with Crohn's disease. It presents as erythematous, scaly plaques on the skin. The lesions respond to treatment of intestinal disease $(43,44)$.

\section{Musculoskeletal:}

Approximately $22 \%$ of the patients with Crohn's disease and $11 \%$ patients with ulcerative colitis present with musculoskeletal manifestations $(3,42,43)$. Arthropathies, ankylosing spondylitis, sacroiliitis, and osteoporosis are some of the more common presentations and will be discussed in this section.

Two types of arthropathies are associated with inflammatory bowel disease and can be seen in $4-23 \%$ of patients. Type I, or large joint pauci-articular arthropathy exhibits a strong correlation with the intestinal inflammation. Control of bowel disease can result in complete resolution of joint symptoms. Type II, or polyarticular arthropathy involves smaller joints. Unlike type I, it does not resolve with control of the bowel disease and requires treatment with noncorticosteroidal anti-inflammatory drugs $(3,42$, 43). 
Synchronous presentation of ankylosing spondylitis and inflammatory bowel disease in seen in about 5 to $10 \%$ of patients. Ankylosing spondylitis initially presents as lower back pain in patients under the age of 30 without any clinical or radiographic evidence of disease. A characteristic morphological change known as "bamboo spine" due to inflexibility caused by fusion of vertebrae develops over a period of years $(3,19)$.

Sacroiliitis is inflammation of the joint between the sacrum and ilium of the pelvis. The condition is seen in association with Crohn's disease, ankylosing spondylitis and arthritis. In most patients, sacroiliitis is asymptomatic. Pain in the pelvic region that is alleviated by movement has been reported in some patients $(3,19)$.

Osteoporosis is characterized by reduced bone density and an increased susceptibility to fractures. It is a frequent finding in patients with inflammatory bowel disease. Corticosteroid use and vitamin D deficiency have been implicated as potential etiological factors. Diet modifications, supplementation of calcium and vitamin D, hormone replacement therapy can be used for treatment (43).

\section{Ocular Manifestations:}

Patients with ulcerative colitis are more likely to present with eye involvement. Scleritis, episcleritis and uveitis are three of the common processes affecting the eyes of patients with ulcerative colitis $(3,31,43)$.

Episcleritis presents as redness of the sclera along with pain and itching. The condition resolves once the bowel disease is under control $(3,19,31)$. 
Scleritis causes redness and severe pain in the eye. If the diagnosis and management are delayed, permanent visual damage may occur. Recurrent inflammation can cause scleromalacia (degeneration and thinning of the sclera), retinal detachment and optic nerve swelling. The condition requires treatment with an aggressive course of systemic corticosteroids to prevent permanent visual impairment $(3,19,31)$.

Uveitis is seen in $0.5-3 \%$ of patients with inflammatory bowel disease. If left untreated, it may lead to blindness. Presenting symptoms include pain, blurred vision, photophobia and headaches. Bilateral involvement is common in patients with ulcerative colitis. Topical and systemic Corticosteroid therapy, and anti-TNF drugs are usually employed to treat the process $(3,19,31)$.

\section{Hepatobiliary Manifestations:}

Hepatobiliary manifestations can be identified in $5-15 \%$ of patients with inflammatory bowel disease. Primary sclerosing cholangitis and gallstones are encountered more frequently and will be discussed in detail in this section. Pericholangitis, steatosis, chronic hepatitis and cirrhosis may also be seen in association with inflammatory bowel disease $(3,19,42,45)$.

Primary sclerosing cholangitis is a chronic inflammatory condition that results in fibrosis of the bile duct. This condition has a strong association with ulcerative colitis, and in rare instances may manifest before the intestinal disease. It is seen more commonly in young men. Patients may present with tiredness, skin irritation, intermittent jaundice and abdominal cramping. Magnetic resonance cholangiography is used to 
establish the diagnosis. Early disease can be usually be controlled by medications. Later in the course of the disease, surgery may be required. Some patients may eventually require liver transplantation $(3,19,42)$.

Gallstones are seen more commonly in association with Crohn's disease. The formation of stones is attributed to the inability of the terminal ileum to absorb bile salts. The condition has a strong female predilection and usually requires surgical intervention $(3,19,45)$.

\section{Pulmonary Manifestations:}

Asthma, bronchiolitis and bronchiectasis are some of the pulmonary conditions that are linked to inflammatory bowel disease. It is estimated that $40-60 \%$ of affected patients have some form of pulmonary involvement. In most cases, the disease presentation is asymptomatic and does not require any medical or surgical intervention (46).

\section{Hematological Manifestations:}

Anemia can be seen in up to $75 \%$ of patients with inflammatory bowel disease. Chronic blood loss from intestinal ulcers and poor absorption of nutrients are two of the etiological factors. Severe anemia presents as pallor, chronic fatigue and dizziness. The diagnosis can be established through routine blood studies. Depending on the type of anemia, iron, vitamin $\mathrm{B}_{12}$ and folic acid supplementation, along with treatment of the underlying intestinal disease, can usually resolve the condition $(19,43)$. 


\section{Chapter 8: Diagnosis and Management of Inflammatory Bowel Disease}

\subsection{Diagnosis:}

The diagnosis of inflammatory bowel disease is made through a multidisciplinary approach, and requires the expertise of a gastroenterologist, radiologist and pathologist. A thorough medical history, comprehensive clinical examination, endoscopic, radiographic and histopathologic evaluations are pertinent for establishing a diagnosis (47). This section provides a summary of the diagnostic and monitoring procedures currently used for inflammatory bowel disease.

\section{Serology:}

C-reactive protein (CRP) is an acute-phase protein produced by the liver in response to systemic inflammation. Protein levels increase in blood after the onset of inflammation, and rapidly decrease following resolution. CRP serves as an effective marker for the presence and remission of Crohn's disease. Its efficacy in monitoring ulcerative colitis is limited.

Erythrocyte sedimentation rate (ESR) serves as a non-specific marker of inflammation for ulcerative colitis. Unlike CRP, it shows a much slower increase and decrease following the onset and resolution of disease. 
Alterations in blood cell counts and protein levels are frequent in patients with inflammatory bowel disease. The changes may either be a result of chronic inflammation or long-term use of anti-inflammatory medications.

Several other acute phase proteins, inflammatory cytokines, anti-neutrophil cytoplasmic antibodies and microbial antigens can be detected through serological studies. The results can be beneficial for both diagnostic and monitoring purposes (48).

Stool Test:

Stool testing is frequently performed in patients with inflammatory bowel disease for gauging inflammation markers because the sample can be obtained non-invasively and swiftly. While fecal inflammation markers are not specific to inflammatory bowel disease, they are more reliable than serological markers. The measurements are not dependent on systemic changes and can be affected only by local factors. Fecal occult blood, alpha-1 antitrypsin, products of the inflammatory cascade (lactoferrin, polymorphonuclear elastase, eosinophil cationic protein, eosinophilic protein $\mathrm{X}$, myeloperoxidase and lysozyme) are released in response to cellular damage and can be important in assessing disease activity (48).

\section{Capsule Endoscopy:}

Capsule endoscopy is performed by swallowing a small camera device that takes high quality images of the intestinal mucosa and transmits to a device worn by the patient. The data from the device can then be downloaded onto a computer and evaluated 
for presence of disease $(49,50)$. The technique is beneficial in identifying mucosal ulceration consistent with either Crohn's disease or non-corticosteroidal antiinflammatory enteropathy. It is simple, non-invasive and can be performed in an outpatient setting. Capsule endoscopy is expensive, time consuming and limited in its ability either to capture images from the large bowel or to perform biopsies. Capsule retention in areas of stricture formation can be a major complication during the procedure, and requires immediate surgical intervention. A patency test using a capsule that has dimensions similar to the camera device and is made of a dissolvable material needs to be performed before the actual device is swallowed $(49,51)$.

\section{Balloon-Assisted Endoscopy:}

Balloon assisted endoscopy is a direct visualization examination of the intestinal tract that can be performed using double- or single-balloon techniques. The inflatable balloons used in the procedure act as anchors and allow for easy advancement of the endoscope through the bowel. The endoscope is equipped with tools to acquire biopsies from areas of interest.

Balloon assisted endoscopy is a relatively safe procedure in which complications are experienced in less than $1 \%$ of the examined population. The drawbacks of this technique include, the need for sedation and limited visibility in some areas (50). 


\section{Spiral Endoscopy:}

Spiral endoscopy is a relatively new procedure that allows for advancement of the endoscope in the bowel by a rotatory motion. Very limited information about the efficacy of this procedure is currently available (50).

\section{Ileocolonoscopy:}

Ileocolonoscopy is the preferred technique for the initial diagnosis and periodic re-evaluation of inflammatory bowel disease. It provides direct visualization of the intestinal mucosa, allowing for assessment of disease activity and screening for colorectal neoplasia. The endoscope can take biopsies, cauterize bleeding ulcers and dilate strictures by placement of stents $(51,52)$. Ileocolonscopy is an invasive procedure that requires sedation. It has limited benefit in evaluating extraluminal disease activity(51).

\section{Computed Tomography Enterography:}

CTE was introduced in 1997 as a modified version of the abdominal CT to evaluate small bowel changes in patients with Crohn's disease (53). Over the years the technology has improved to limit radiation exposure and provide better imaging (54). In comparison to endoscopy and barium studies, this technique is useful, non-invasive, well tolerated and easily performed (53). High costs and technique sensitivity are the primary disadvantages of the procedure (48). 
Magnetic Resonance Enterography:

Like CTE, magnetic resonance enterography provides imaging of the luminal and extraluminal tissue. The procedure is non-invasive, radiation-free and well tolerated in patients of all ages. It can be performed safely in pregnant women. Magnetic resonance imaging is contraindicated in patients with metallic devices, such as implants and pacemakers. Patients with claustrophobia may find the confined imaging chamber difficult to tolerate (51).

\section{Ultrasonography:}

Transabdominal ultrasonography was first used as a diagnostic aid for inflammatory bowel disease in the 1970s (55). Its use is now limited due to availability of better imaging techniques (48).

Combinations of ultrasonography with endoscopy have also been attempted. While the combination procedure is able to detect defects in the bowel more effectively, it is unable to distinguish Crohn's disease from ulcerative colitis (55).

\section{Pathology:}

The 2013 guidelines from the European consensus on histopathology of inflammatory bowel disease recommend biopsies from "five sites along the colon, including the rectum, and the terminal ileum" for initial diagnosis. The tissue submitted for histopathologic examination needs to be formalin-fixed. Gross examination of the 
specimen allows for location of obvious pathology and determines the appropriate site for sectioning. Hematoxylin and eosin staining is adequate for histopathologic evaluation (47).

\section{Crohn's Disease:}

Macroscopic examination of the gross specimen reveals alternating areas of normal and inflamed mucosa ("skip lesions"). A sharp transition is usually seen between affected and unaffected areas. The affected area appears erythematous and may exhibit serosal adhesions. During the earlier phases of disease, small ulcers are noted in the intestinal mucosa. Over time, these small ulcers coalesce to form larger defects. The edematous tissue between the ulcers gives rise to the characteristic cobblestone appearance of Crohn's disease. Healing of ulcers may be accompanied by scarring and

often results in intestinal strictures. Enveloping of the intestinal wall by the serosal fat tissue is a frequent finding, this process is referred to as "fat wrapping" $(47,56)$. Sinus tracts, fistulous tracts and abscesses are seen more frequently in patients with Crohn's disease than those with ulcerative colitis $(56,57)$. Regional lymphoid hyperplasia is a frequent, non-specific feature noted in association with this process (58).

Microscopically, Crohn's disease is characterized by focal areas of chronic inflammation, crypt architectural distortion and occasional granuloma formation. The inflammatory infiltrate is predominantly comprised of lymphocytes and involves the entire thickness of the intestinal wall. Patchy infiltrates of chronic cells are noted in nonulcerated regions of the intestine. Abscesses are rarely seen $(47,58)$.The characteristic 
granulomas associated with Crohn's disease are non-necrotizing and are composed of occasional giant cells interspersed among a population of epithelioid histiocytes (47). Granulomatous inflammation may be noted in up to $60 \%$ of the patients affected by Crohn's disease (58). These granulomas are significantly different than the "mucin granulomas" that form due to the collection of macrophages following crypt rupture. Mucin granulomas are not specific to Crohn's disease, and may also be noted in other intestinal diseases. Submucosal fibrosis may occur as part of the healing process, and this usually results in stricture formation (56).

Due to overlapping histopathologic features, it may be become difficult to distinguish between Crohn's disease and ulcerative colitis. Occasionally ulcerative colitis may present with discontinuous disease, aphthous- like ulceration or mural inflammation. Similarly, Crohn's disease may present with continuous involvement of the colon, superficial ulceration and a complete absence of mural inflammation. In such instances, a review of the clinical, radiographic and endoscopic examination and previous biopsies usually assists in establishing a definitive diagnosis (57).

\section{Ulcerative Colitis:}

The macroscopic appearance of the resected tissue would depend on the extent of involvement with the disease process, and the type and intensity of the inflammatory infiltrate (56). Active disease usually presents as erythematous and friable mucosa that strips away easily to form large ulcers (58). A sharp delineation between normal and inflamed mucosa is noted (47). Inactive ulcerative colitis either appears grossly normal or 
exhibits a significant degree of mucosal atrophy (56). Inflammatory pseudopolyps are frequently seen in association with severe disease involvement. They represent elevated areas adjacent to colonic defects that have the tendency to irritate proximate tissue and result in additional ulceration $(47,56,58)$. The patterns of inflammation may be different in patients undergoing topical or systemic treatment (47). Remission is characterized by decrease in mucosal erythema and ulceration. The mucosa may still appear atrophic and uneven $(56,58)$. Long-term involvement may lead to fibrosis, and eventual stricture formation in some patients (47). Sinus tracts and fistulas are rare in ulcerative colitis (57).

The histopathologic appearance of ulcerative colitis varies according to severity of involvement. In early disease stages, basal plasmacytosis may be the only identified feature, requiring re-biopsy of the tissue six weeks later. Later stages of disease are characterized by destruction of the normal villous architecture along with a diffuse or continuous inflammatory infiltrate consisting of neutrophils, plasma cells, lymphocytes, eosinophils and occasionally mast cells. Disease activity is dependent on the neutrophilic accumulation within the colonic mucosa, with mild activity characterized by low numbers of neutrophils in the cryptic epithelium. Severe disease presents as large abscesses resulting in complete destruction of the crypt architecture. In non-ulcerated areas, blood vessels appear engorged and extravasation of erythrocytes is seen. The crypts appear atrophic and show frequent branching. Goblet cells appear to be decreased in number and Paneth cell metaplasia is frequently noted. Granulomas are seen only in association with ruptured crypts $(57,58)$. In quiescent stages of the disease, some tissue regeneration along with villous distortion is seen. The inflammatory infiltrate is either 
minimal or absent during this phase. Clinical relapse is characterized by return of the inflammatory cells to the area. Remission results in complete restoration of the crypt architecture and the resolution of inflammation (47).

Patients with ulcerative colitis exhibit a higher risk for colorectal cancers. The cancers appear to develop in areas of chronic inflammation. Recent guidelines call for continuous surveillance with frequent endoscopic evaluation and histopathologic examination for dysplasia, especially in patients who have had the disease for over eight years (47).

Cytomegalovirus identification is pertinent in patients with ulcerative colitis as they have 10 to $56.7 \%$ higher chance of acquiring this infection compared to the general population. Testing for reactivation of cytomegalovirus is especially important in patients who do not respond to conventional treatment (47).

\subsection{MANAGEMENT:}

\section{Crohn's Disease:}

\section{Medical Management of Crohn's Disease:}

The following paragraphs summarize the available treatment options for patients with Crohn's disease. The choice of drug is dependent on intestinal disease activity. In some patients more than one drug may be employed to induce remission. 
Aminosalicylic Acid Derivatives:

The effectiveness of aminosalicylates in Crohn's disease is minimal and these formulations are no longer recommended by the American Academy of Gastroenterology (21).

Antibiotics:

The use of antibiotics in Crohn's disease should be limited for suppurative processes, such as fistulous tracts, abscesses, pouchitis, post-surgical resections or perianal disease. Despite traditional practices, antibiotics have very little effect on disease progression $(21,59)$.

\section{Corticosteroids:}

Corticosteroids such as prednisone, hydrocortisone and budesonide are usually the first line of drugs employed to control disease progression. Corticosteroids are able to induce remission in over $70 \%$ of patients with Crohn's disease, in comparison to $30 \%$ with placebo. Due to the significant side effects associated with long-term use of these drugs, they can only be administered on a short-term basis (59). 


\section{Immunomodulators:}

Immunomodulators such as azathioprine, 6-mercaptopurine and methotrexate are used in patients with corticosteroid-dependent disease as maintenance therapy. The corticosteroid-sparing effect of these drugs allows patients to gradually taper off corticosteroids.

Immunomodulators are associated with some significant side-effects, including predisposition to infectious and neoplastic diseases, bone marrow suppression and liver damage. Constant monitoring is usually necessary in patients taking these drugs (21).

\section{Biologic Therapy:}

The use of biologic agents for managing inflammatory processes is continually rising. The anti-tumor necrosis factor (anti-TNF) effect of these drugs allows for both induction and maintenance of remission in patients with Crohn's disease. The Federal Drug Administration (FDA) has approved three formulations for use in the United States: infliximab, adalimumab and certolizumab pegol. Response rates of over $81 \%$ and remission rates of over 33\% have been reported for infliximab.

Anti-TNF agents are expensive and associated with an increased risk of infectious and neoplastic diseases. There is also a slight chance of developing psoriasis. Periodic use of these medications can lead to antibody formation against the drug, making the patient refractory to treatment (21). 


\section{Surgical Management of Crohn's Disease:}

Surgery is reserved for patients with disease that is refractory to medical treatment, or those with perforations, strictures or stenosis, fistulous tracts and abscess formation. Conservative surgical approaches are preferred in patients with Crohn's disease.

\section{Strictureplasty:}

Strictureplasty is a conservative procedure that allows for preservation of the bowel length. Strictures longer than $25 \mathrm{~cm}$ in length can be managed by this procedure. The surgical technique employed for corrective purposes is dependent on the length and rigidity of the stricture.

The procedure is relatively safe with low incidences of morbidity and mortality. The success of strictureplasty is similar to resection procedures. Strictureplasty is contraindicated in cases of perforation, hypoalbuminemia, multiple strictures at short distances, and strictures in close proximity to areas of resection.

\section{Laparoscopic Resection:}

This procedure is indicated in cases of disease that is refractory to medical treatment, in patients who can no longer tolerate medical therapy, or in cases of hemorrhage and obstruction. The use of laparoscopy in Crohn's disease is limited, as 
surgeons tend to prefer an open approach in urgent cases. The laparoscopic procedure takes a longer time but is associated with faster post-operative healing.

\section{Segmental Resection:}

The procedure is reserved for cases in which inflammation is localized to a small part of the bowel and involves complete resection of the diseased portion. While this may provide short-term relief, there is a high risk of recurrence in a different part of the bowel.

\section{Total Colectomy with Ileo-rectal Anastomosis:}

In cases in which the rectum is spared from the disease process, complete resection of the colon followed by a union of the ileum to the rectum can be performed. Even after the complete removal of the inflamed part of the intestine, there is a $50 \%$ chance of the inflammation occurring at a different site. The patient may require an ileostomy at some point in the future.

\section{Proctocolectomy with Permanent Ileostomy:}

This procedure is associated with a $15-25 \%$ chance of recurrence. Post-operative healing time is extended and the patient has recurrent episodes of perianal disease and cutaneous involvement. 
Perianal Disease:

Perianal abscesses require urgent drainage in order to avoid widespread damage, especially to the sphincters. Only symptomatic fistulous tracts are treated. In most instances, antibiotics such as metronidazole and ciprofloxacin are sufficient to seal fistulous tracts. Persistent or recto-vaginal fistulas may need to be repaired surgically (59, $60)$.

\section{Ulcerative Colitis:}

The management of ulcerative colitis depends on the severity of disease. Efficacy of treatment is determined by its ability to induce remission and maintain it on a long term basis.

\section{Medical Management:}

Aminosalicylic Acid Derivatives:

Aminosalicylates, such as mesalazine, sulfasalazine, olsalazine and balsalazide, are the initial drugs used for management of mild to moderate ulcerative colitis. 5aminosalicylic acid has anti-inflammatory properties that allow for remission of the disease process. The medication is available as tablets, suppositories and enemas. Studies have shown that suppositories and enemas can be more effective in controlling local symptoms than oral formulations. Long-term use is associated with a lower risk of 
colorectal cancer. The drug is usually well-tolerated by patients and is associated with only minor side effects (61).

\section{Glucocorticoids:}

Patients that do not show resolution of symptoms with aminosalicylic acid are placed on corticosteroid therapy. Oral or intravenous prednisone is usually the drug of choice. Doses between 40 and $60 \mathrm{mg}$ daily are sufficient to control symptoms in over $70 \%$ patients. Due to significant side effects associated with long-term corticosteroid use, prednisone is used only during flares of disease and terminated once the symptoms are under control. Half of the patients responding to the corticosteroids will require additional courses of medication to manage future episodes. About $22 \%$ of patients treated with prednisone develop corticosteroid dependency. Corticosteroid usage in ulcerative colitis is linked to poor prognosis with over $29 \%$ of patients requiring surgical management at some point in the future (61-63).

\section{Azathioprine:}

Azathioprine and mercaptopurine are immunomodulators that are used in patients who develop corticosteroid dependency. They can be used in conjunction with tapering doses of corticosteroids or anti-TNF agents to induce remission (61). The efficacy of azathioprine and mercaptopurine is limited (63). 


\section{Cyclosporine:}

Cyclosporine and tacrolimus are immunosuppressive drugs that are highly effective in controlling severe symptoms of ulcerative colitis. These drugs have been approved only for short-term use due to their significant side effects (63). In about $82 \%$ of patients, immediate response is seen with the use of cyclosporine. However, most patients tend to relapse within a couple of years (62).

\section{Infliximab:}

Infliximab and adalimumab are anti-TNF agents that are used for the treatment of autoimmune processes. Both drugs are administered intravenously. Studies have indicated that these biological agents are able to improve clinical symptoms and induce mucosal healing in over $70 \%$ of patients. Following induction, infliximab treatment is taken every eight weeks while adalimumab is taken every two weeks (63).

\section{Methotrexate:}

Methotrexate can be tried as a treatment option in some individuals. This practice is more common in pediatric patients. Regular blood studies are necessary to ensure normal blood counts and liver enzymes $(61,62,64)$. 


\section{Surgical Management of Ulcerative Colitis:}

About $25 \%$ of patients with ulcerative colitis undergo a surgical procedure at some point. Surgical intervention can be due to refractory disease, inability to use longterm anti-inflammatory medications, or presence of neoplastic disease. While the surgery may result in complete resolution of symptoms, it is also associated with some risks and complications, such as strictures, pouch problems, fertility issues and impotence.

\section{Emergent Operative Management:}

This procedure is indicated for the management of fulminant colitis and involves the complete removal of the abdominal colon and an end ileostomy. The patients usually respond well to the procedure. Most patients can discontinue the use of anti-inflammatory medications following the surgery.

\section{Elective Operative Management:}

1. Restorative Proctocolectomy with Ileal Pouch - Anal Anastomosis:

This procedure involves complete colectomy followed by pelvic dissection. The nerves of the pelvic region and the anal sphincter are spared. A reservoir is created from the distal 40 centimeters of the ileum in the shape of the letter "J". The pouches can also be created in the shape of the letters $\mathrm{S}, \mathrm{W}$ and $\mathrm{H}$. 
The procedure usually has a fair prognosis. About 19\% patients that undergo the procedure may experience some form of complication. Mortality rates are between 0.2$0.4 \%$.

\section{Staged Procedures:}

Restorative proctocolectomy can also be performed in two stages. In stage one, loop ileostomy is created to reroute the fecal material, and the pouch is anastomosed to the anus. Diversion of the fecal materials allows for uneventful healing of the pouch-anal anastomosis. At stage two, the connection between the ileum and the pouch is restored.

\section{Laparoscopic Approaches:}

Restorative proctocolectomy by laparoscopic procedures is associated with reduced post-operative pain, and healing time.

\section{Total Proctocolectomy with Ileostomy:}

This procedure is reserved for older individuals, patients with impaired sphincter function or those with neoplastic disease. Over $25 \%$ of the patients undergoing the procedure experience some form of complication.

\section{Subtotal Colectomy with Ileorectal Anastomosis:}

The procedure involves connecting the ileum directly to the rectum. While most patients respond well to the procedure, some patients may experience frequent bowel 
movements and proctitis. About $25 \%$ of the patients that undergo this procedure will eventually undergo proctectomy due to persistence of disease or development of neoplasia.

6. Proctocolectomy with a Koch Pouch:

A Koch pouch is surgically created from the ileum to collect fecal matter. The material collected in the pouch needs to be drained through a valve. The procedure is recommended for patients that have impaired sphincter functions or have failed more conventional surgical procedures (65).

\subsection{Prognosis:}

Over $73 \%$ of patients with inflammatory bowel disease experience flares followed by periods of remission. In about $13 \%$ of affected individuals, the disease follows an unremitting course. Prolonged periods of remission can be seen in about $10 \%$. About $57 \%$ of the patients will undergo at least one surgical procedure during the course of their disease (66). 


\section{Chapter 9: Oral Manifestations of Inflammatory Bowel Disease}

Oral involvement with inflammatory bowel disease was first reported in 1969 by Dudeney (4) and Dyer et al (5) in two separate reports. Dudeney documented a case of an exophytic growth on the buccal mucosa of a 36-year-old male patient with a prior diagnosis of Crohn's disease. The biopsy of lesional tissue exhibited granulomatous inflammation. Based on these findings, Dudeney suggested a possible link between the oral and intestinal processes (4). The same year Dyer and colleagues reported a case of recurrent aphthous ulceration in a patient who was later diagnosed with Crohn's disease (5). Since then several reports and studies have documented the presence of oral lesions in patients with inflammatory bowel disease. Most oral alterations linked to this condition are characteristic, and are uncommonly seen in association with other disease processes.

Oral inflammatory bowel disease may present as gingival plaques or hyperplasia, mucosal swelling, a "cobblestone" mucosal alteration, linear vestibular ulceration, mucosal tags and pyostomatitis vegetans. Oral lesions may present synchronously with intestinal inflammation or may precede it by several years. Oral involvement following resolution of intestinal disease has also been described. Although the disease course of oral involvement is not fully understood, current data indicates that the presence of oral lesions have no correlation with disease activity $(15-17,23)$. 


\section{Epidemiology:}

Oral manifestations of inflammatory bowel disease are more frequent in children. A male predisposition is noted by some investigators (6). The prevalence in adults is estimated to be somewhere between $0.5-9 \%(8,9)$. Patients with Crohn's disease appear to be at a higher risk for developing oral manifestations than patients with ulcerative colitis $(6,7)$.

\section{Controversy over Terminology:}

The use of the term 'orofacial granulomatosis' synonymously for oral Crohn's disease has generated some controversy. Some authors are of the opinion that the identical clinical presentation and histopathology of the two conditions suggests that they are a common process (67). They support this theory based on the fact that oral presentation may precede or succeed intestinal symptoms by several years, indicating that the lack of intestinal involvement at a particular point in time does not necessary mean the absence of it $(17,68)$.

Others argue that the diagnosis of oral Crohn's disease can be made only in the presence or history of intestinal involvement (67). They base their argument on the notion that features consistent with orofacial granulomatosis can be seen in association with other autoimmune processes, such as cheilitis granulomatosa, sarcoidosis, and Melkerson-Rosenthal syndrome. The study by Sanderson and colleagues in 2005 attempted to estimate the prevalence of intestinal disease in patients with orofacial 
granulomatosis. They were able to identify intestinal involvement in only $54 \%$ of the patients. (69).

\section{Clinical Features:}

Inflammatory bowel disease involving the mouth has a very characteristic appearance, although the oral lesions linked to this process are not unique and may be seen in other autoimmune processes. Therefore, their presence warrants a detailed evaluation of the gastrointestinal tract. This section details the specific and non-specific oral alterations reported in patients with inflammatory bowel disease.

\section{Gingival Erythema and Hyperplasia:}

Gingival lesions associated with inflammatory bowel disease manifest as multiple, erythematous plaques with a velvety texture (Figure 1). Occasionally, generalized edematous swelling of the gingival tissues may also be seen. While attached gingiva is more frequently involved, lesions may extend to the mucogingival junction. Superficial ulcerations of the hyperplastic gingiva may result in significant pain or discomfort $(7,11)$.

\section{Mucosal Swelling:}

Patients with Crohn's disease may present with diffuse, non-tender mucosal swelling. Lips and buccal mucosa are most commonly involved. Either one lip or both of the lips can exhibit involvement (Figure 2). Presence of a central lip fissure is not 
uncommon. The swollen tissue is usually edematous and may feel firm on palpation. While the condition is not painful, cosmetic concerns usually induce patients to seek medical help $(7,10,11)$.

\section{Cobblestoning:}

Cobblestoning refers to diffuse nodular swellings that impart a "bumpy" appearance to the mucosa, similar to the surface of a cobblestone street. This surface change of the mucosa may occur as a solitary process or in conjunction with linear vestibular ulceration. The buccal mucosa is most commonly affected. While the process is primarily asymptomatic, difficulty in eating and talking has been reported $(7,10,11)$.

\section{Linear Vestibular Ulceration:}

Patients with Crohn's disease may present with linear ulcers extending along the length of the vestibule (Figure 3). The ulcers may be the only presentation of disease or may occur in association with mucosal tags and cobblestoning. Mandibular buccal vestibule is a frequent site of involvement. The ulcers usually cause significant discomfort and pain $(7,10,11)$.

\section{Mucosal Tags:}

Mucosal tags can be described as soft tissue swellings that resemble dentureinduced fibrous hyperplasia. The lesions may appear as small tags or folds, and occasionally they develop adjacent to linear vestibular ulceration (Figure 4). Labial and 
buccal vestibules are more commonly involved. Fibrous hyperplasia secondary to chronic inflammation is implicated as a possible etiology of these soft tissue tags. The lesions are usually asymptomatic $(7,10,11)$.

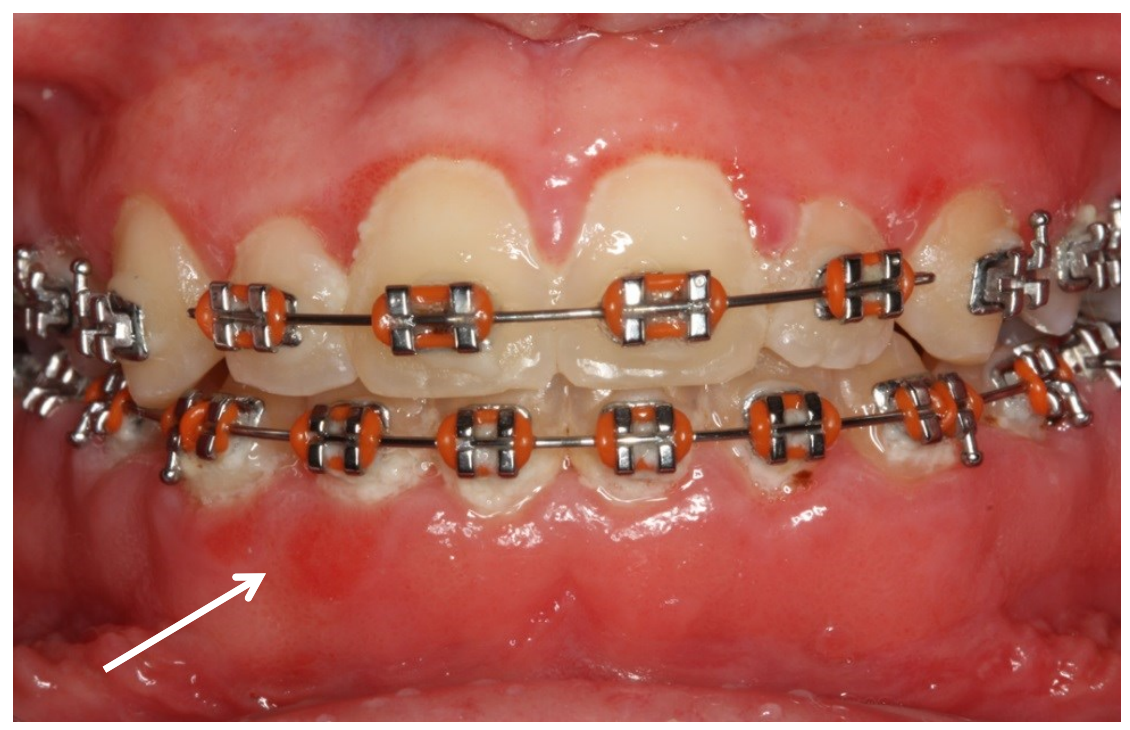

Figure 1: Erythematous plaques consistent with gingival erythema.

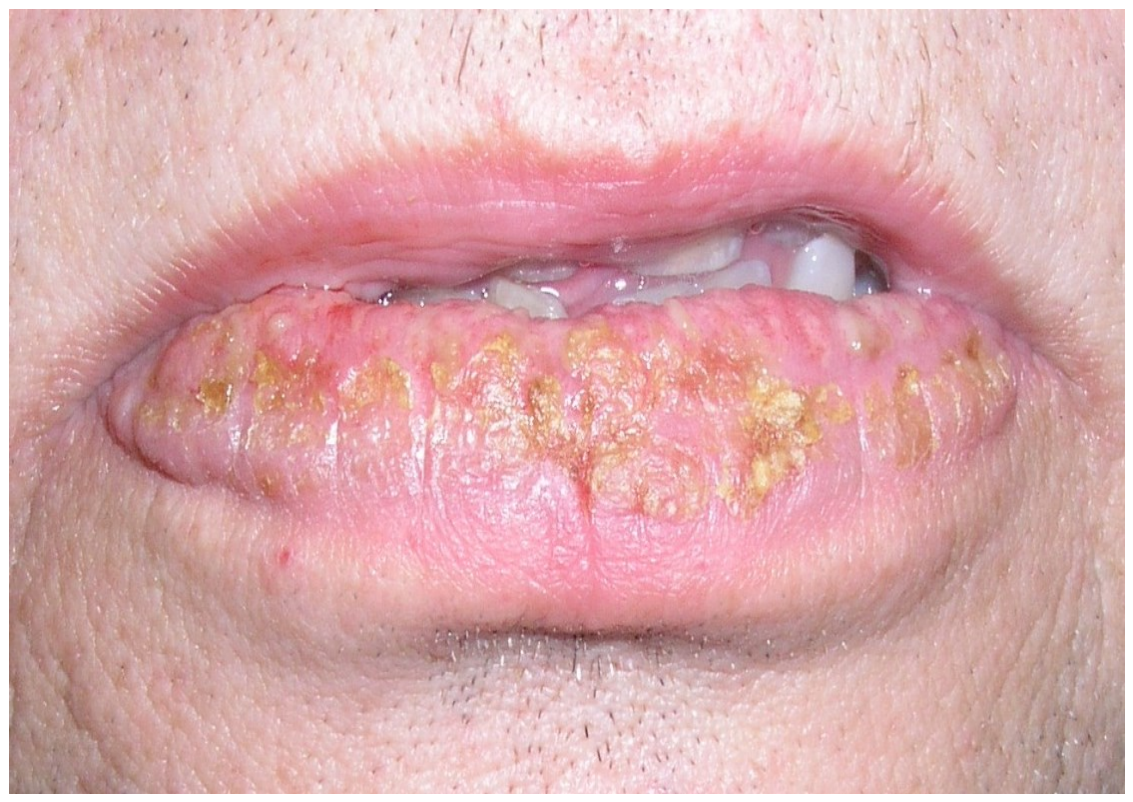

Figure 2: Lip swelling in a patient with Crohn's disease. (Courtesy of Dr. Yeshwant Rawal) 


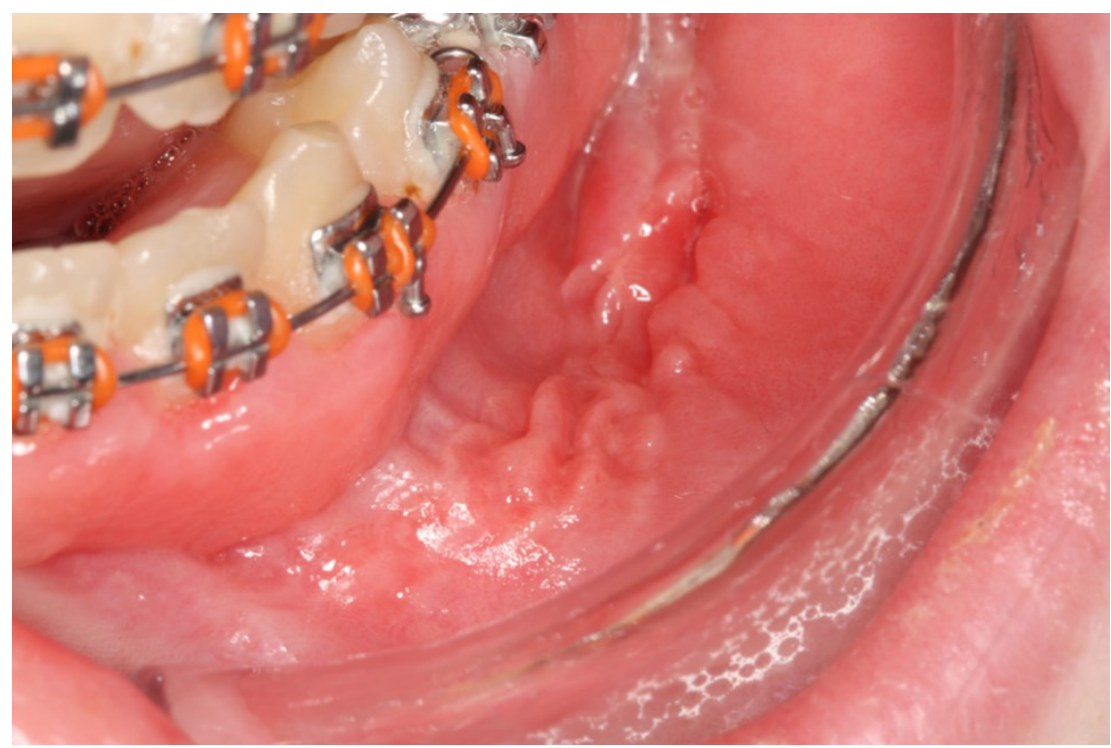

Figure 3: Linear vestibular ulceration in association with mucosal tags.

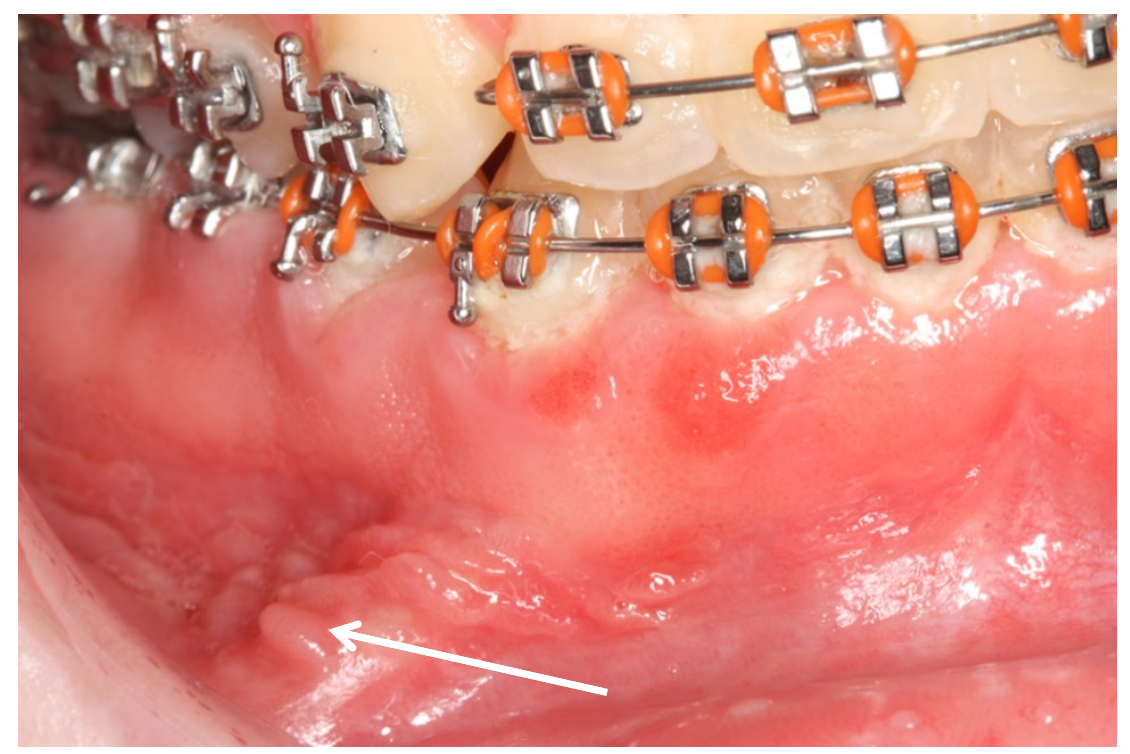

Figure 4: Mucosal tags in the buccal vestibule. Areas of gingival erythema are also visible. 


\section{Pyostomatitis Vegetans:}

Pyostomatitis vegetans is a rare condition that has been reported in association with various autoimmune disorders, such as pemphigus, pyoderma gangrenosum and inflammatory bowel disease. Pyostomatitis vegetans is characterized by areas of edematous and inflamed oral mucosa with numerous small, yellow pustules (Figure 5). Adjacent pustules coalesce to form larger "snail-track ulcers". The lesions usually involve the gingiva, buccal mucosa, palate and ventral tongue. The tonsillar and labial mucosa may also be involved. Pain is a frequent complaint in patients with pyostomatitis vegetans. About $90 \%$ of patients with this condition present with peripheral eosinophilia $(7,10,70,71)$.

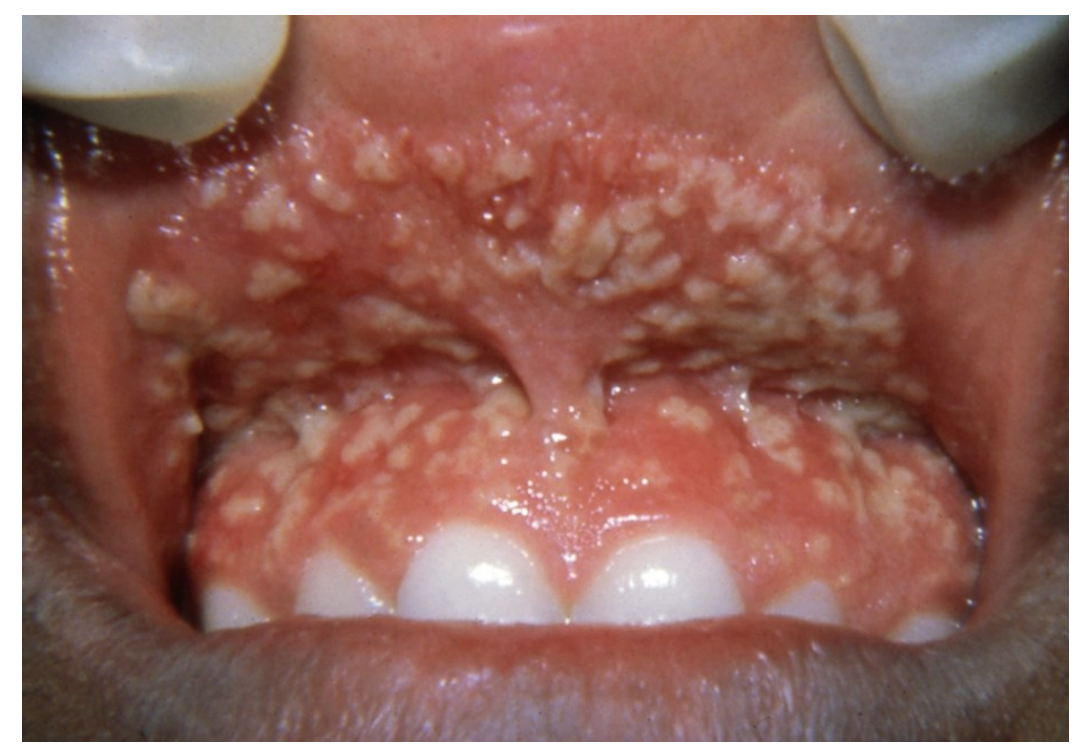

Figure 5: Clinical picture exhibiting "snail track ulceration" of the attached gingiva and labial mucosa in a patient with pyostomatitis vegetans. (Courtesy of Dr. Terry Kelley). 


\section{Non-Specific Oral Lesions:}

A range of non-specific oral lesions have been linked to inflammatory bowel disease. Aphthous ulceration, oral candidiasis and erythema migrans are some of the more common ones. Several well controlled studies, however, show a similar frequency of these processes in patients with inflammatory bowel disease compared to healthy controls $(10,13,14,72)$.

\section{Other Oral Disturbances Linked to Inflammatory Bowel Disease:}

A few studies have reported a higher prevalence of dental caries and periodontal disease in patients with inflammatory bowel disease. These results are controversial and have been challenged by others. Xerostomia, dysgeusia, nausea, vomiting, halitosis, burning mouth, dysphagia and regurgitation have also been linked to the intestinal disease $(13,73,74)$. A study in 2003 by Katz examined these parameters, comparing their frequency in patients with inflammatory bowel disease compared to a normal control population. The results were significant for an increased incidence of nausea, vomiting, regurgitation, xerostomia and halitosis. All other entities were found to be equally prevalent in the control population (75).

\section{Diagnosis:}

The characteristic clinical presentation and history of inflammatory bowel disease are helpful in suggesting a diagnosis of oral mucosal lesion associated with inflammatory 
bowel disease. Biopsy of lesional tissue, however, is necessary to confirm diagnosis. The following section details the histopathologic findings in patients with oral inflammatory bowel disease.

\section{Histopathologic Findings in Oral Crohn's Disease:}

Histopathologic examination of biopsy specimens from the oral mucosa shows neutrophils and lymphocytes infiltrating the surface epithelium. The underlying connective tissue supports non-caseating granulomas with epithelioid macrophages and Langerhans-type giant cells (Figure 6). Populations of lymphocytes, plasma cells and histiocytes along with perivascular lymphocytic infiltrates are also identified. Special stains for microorganisms are negative $(10,13,18)$.

In some instances, no granulomas are identified. The surface epithelium is usually ulcerated and the underlying connective tissue supports diffuse populations of chronic inflammatory cells. Perivascular infiltrates are frequently noted along with occasional neuronal hyperplasia and intimal thickening (13).

Estimates of oral biopsies exhibiting characteristic granuloma formation vary from $10 \%$ to $68 \%(6,13)$. As with intestinal disease, presence of granuloma formation is not necessary for making the diagnosis of Crohn's disease. Other granulomatous

conditions such as Melkelson-Rosenthal syndrome, cheilitis granulomatosa and sarcoidosis need to be ruled out before a definitive diagnosis is made. 


\section{Histopathologic Examination of Pyostomatitis Vegetans:}

Pyostomatitis vegetans has very characteristic histopathologic features consisting of acanthotic stratified squamous epithelium that exhibits areas of ulceration. Collections of neutrophils and eosinophils can be identified in the spinous layer of the epithelium

(Figure 7). Subepithelial eosinophilic abscesses may be identified in some instances. The underlying connective tissue supports large populations of predominantly chronic inflammatory cells $(12,70)$.

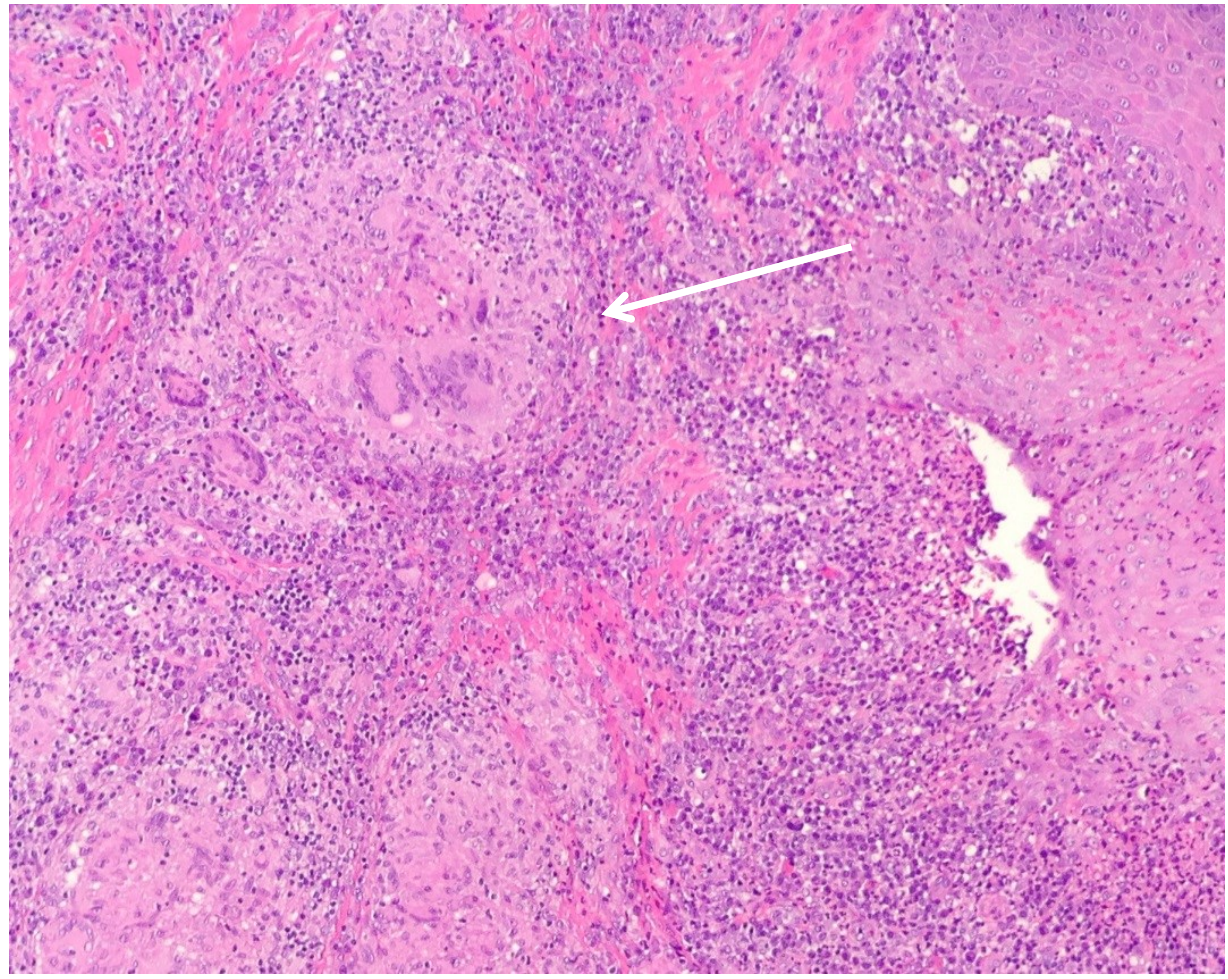

Figure 6: Non-caseating granulomatous inflammation in a patient with Crohn's disease. 


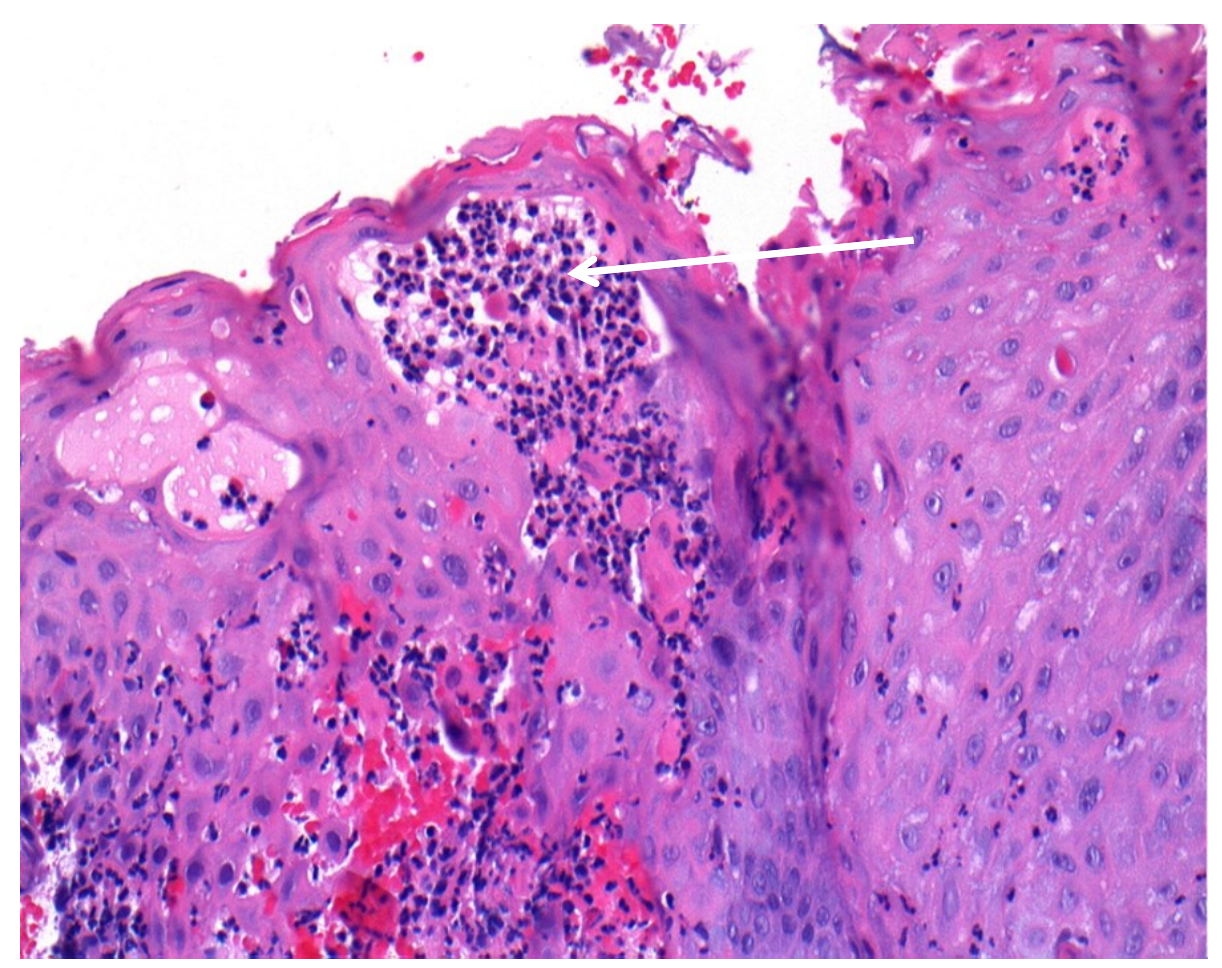

Figure 7: Eosinophilic micro-abscess formation consistent with pyostomatitis vegetans.

\section{Management:}

\section{Treatment and Course of Oral Crohn's Disease:}

Tyldesley and Field followed five patients with oral Crohn's disease over a course of 10 years. Almost all patients had presented with swollen lips, painful linear ulceration and angular cheilitis at the initial visit. Palpable submental lymph nodes and non-specific gingivitis was also identified in some of these patients. Systemic corticosteroids were helpful in controlling symptoms, however recurrence of oral disease was noted as soon as the treatment was stopped. Lip swelling and buccal ulceration eventually resolved during the 10-year period. Persistence of angular cheilitis was observed in one case (18). 
According to a study published by Dupuy and colleagues, seven patients with oral lesions were identified between the years 1975-1997. These patients were followed for periods ranging between 2 and 24 years. The oral lesions persisted for twelve months in each of the patients. Topical treatment with corticosteroids and other anti-inflammatory agents induced remission of oral lesions in about $50 \%$ of patients. In patients refractory to topical treatment, resolution was seen following administration of systemic corticosteroids (76).

Hussey and colleagues followed 24 pediatric patients that presented with oral manifestations of Crohn's disease over a period of 22-97 months. Only 29\% (7/24) had persistent disease at follow-up. The course of their oral disease was independent of intestinal activity, and gradual resolution was noted even when no treatment was administered (77).

\section{Treatment for Oral Pyostomatitis Vegetans:}

Topical treatment with corticosteroids is usually ineffective in treating pyostomatitis vegetans. Systemic corticosteroids, azathioprine, dapsone, or sulfamethoxypyridazine can usually control the disease process (7).

Although oral manifestations of inflammatory bowel disease are rare, they may result in significant discomfort. The characteristic clinical presentation is usually helpful in establishing a diagnosis, especially when there is a known history of inflammatory 
bowel disease. It is important for oral and medical healthcare professionals to recognize these alterations so they can assist their patients to seek appropriate healthcare. 


\section{References:}

1. Mulder DJ, Noble AJ, Justinich CJ, Duffin JM. A tale of two diseases: The history of inflammatory bowel disease. Journal of Crohn's \& colitis. 2014;8(5):341-8.

2. Wang YR, Loftus EV, Jr., Cangemi JR, Picco MF. Racial/Ethnic and regional differences in the prevalence of inflammatory bowel disease in the United States. Digestion. 2013;88(1):20-5.

3. Ardizzone S, Puttini PS, Cassinotti A, Porro GB. Extraintestinal manifestations of inflammatory bowel disease. Digestive and liver disease : official journal of the Italian Society of Gastroenterology and the Italian Association for the Study of the Liver. 2008;40 Suppl 2:S253-9.

4. Dudeney TP. Crohn's disease of the mouth. Proceedings of the Royal Society of Medicine. 1969;62(12):1237.

5. Dyer NH, Cook PL, Kemp Harper RA. Oesophageal stricture associated with Crohn's disease. Gut. 1969;10(7):549-54.

6. Plauth M, Jenss H, Meyle J. Oral manifestations of Crohn's disease. An analysis of 79 cases. Journal of clinical gastroenterology. 1991;13(1):29-37.

7. Lankarani KB, Sivandzadeh GR, Hassanpour S. Oral manifestation in inflammatory bowel disease: a review. World journal of gastroenterology : WJG. 2013;19(46):8571-9.

8. Cosnes AD, J. Revus, JC.Delchier, JF. Contou, JP. Gendre, J. Longterm evolution of oral localisation of Crohn's disease (abstract). Gastroenterology. 1998;114(4):1.

9. Asquith P, Thompson RA, Cooke WT. Oral manifestations of Crohn's disease. Gut. 1975;16(4):249-54.

10. Kalmar JR. Crohn's disease: orofacial considerations and disease pathogenesis. Periodontology 2000. 1994;6:101-15.

11. Neville BD, DD. Allen, CM. Bouqout, JE. Crohn's disease. Oral and maxillofacial pathology. 3rd ed. St. Louis, MO: Saunders Elsevier; 2009. p. 848-9.

12. Neville BD, DD. Allen, CM. Bouqout, JE. Pyostomatitis vegetans. Oral and maxillofacial pathology. St. Louis, MO: Saunders Elsevier; 2009. p. 850.

13. Basu MK, Asquith P. Oral manifestations of inflammatory bowel disease. Clinics in gastroenterology. 1980;9(2):307-21.

14. Lisciandrano D, Ranzi T, Carrassi A, Sardella A, Campanini MC, Velio P, et al. Prevalence of oral lesions in inflammatory bowel disease. The American journal of gastroenterology. 1996;91(1):7-10.

15. Ghandour K, Issa M. Oral Crohn's disease with late intestinal manifestations. Oral surgery, oral medicine, and oral pathology. 1991;72(5):565-7.

16. Galbraith SS, Drolet BA, Kugathasan S, Paller AS, Esterly NB. Asymptomatic inflammatory bowel disease presenting with mucocutaneous findings. Pediatrics. 2005;116(3):e439-44. 
17. Scully C, Cochran KM, Russell RI, Ferguson MM, Ghouri MA, Lee FD, et al. Crohn's disease of the mouth: an indicator of intestinal involvement. Gut. 1982;23(3):198-201.

18. Field EA, Tyldesley WR. Oral Crohn's disease revisited--a 10-year-review. The British journal of oral \& maxillofacial surgery. 1989;27(2):114-23.

19. Trikudanathan G, Venkatesh PG, Navaneethan U. Diagnosis and therapeutic management of extra-intestinal manifestations of inflammatory bowel disease. Drugs. 2012;72(18):2333-49.

20. Belenguer-Guallar I, Jimenez-Soriano Y, Claramunt-Lozano A. Treatment of recurrent aphthous stomatitis. A literature review. Journal of clinical and experimental dentistry. 2014;6(2):e168-e74.

21. Cheifetz AS. Management of active Crohn disease. JAMA : the journal of the American Medical Association. 2013;309(20):2150-8.

22. Hyams JS. Extraintestinal manifestations of inflammatory bowel disease in children. Journal of pediatric gastroenterology and nutrition. 1994;19(1):7-21.

23. Harty S, Fleming P, Rowland M, Crushell E, McDermott M, Drumm B, et al. A prospective study of the oral manifestations of Crohn's disease. Clinical gastroenterology and hepatology : the official clinical practice journal of the American Gastroenterological Association. 2005;3(9):886-91.

24. Griffiths AM. Inflammatory bowel disease. Nutrition. 1998;14(10):788-91.

25. Panés J. Inflammatory bowel disease: pathogenesis and targets for therapeutic interventions. Acta Physiologica Scandinavica. 2001;173(1):159-65.

26. Geier MS, Butler RN, Howarth GS. Inflammatory bowel disease: Current insights into pathogenesis and new therapeutic options; probiotics, prebiotics and synbiotics. International journal of food microbiology. 2007;115(1):1-11.

27. Baumgart DC, Sandborn WJ. Inflammatory bowel disease: clinical aspects and established and evolving therapies. Lancet. 2007;369(9573):1641-57.

28. Metcalf C. Crohn's disease: an overview. Nursing standard (Royal College of Nursing (Great Britain) : 1987). 2002;16(31):45-52; quiz 4-5.

29. Gurenlian JR. Crohn's Disease. Access. 2003;17(3).

30. Louis E, Collard A, Oger AF, Degroote E, Aboul Nasr El Yafi FA, Belaiche J. Behaviour of Crohn's disease according to the Vienna classification: changing pattern over the course of the disease. Gut. 2001;49(6):777-82.

31. Karlinger K, Gyorke T, Mako E, Mester A, Tarjan Z. The epidemiology and the pathogenesis of inflammatory bowel disease. European journal of radiology. 2000;35(3):154-67.

32. Hanauer SB. Inflammatory bowel disease. The New England journal of medicine. 1996;334(13):841-8.

33. Boirivant M, Cossu A. Inflammatory bowel disease. Oral diseases. 2012;18(1):1-

15.

34. Farrell RJ, Peppercorn MA. Ulcerative colitis. Lancet. 2002;359(9303):331-40.

35. Ford AC, Moayyedi P, Hanauer SB. Ulcerative colitis. BMJ (Clinical research ed). 2013;346:f432. 
36. Thoreson R, Cullen JJ. Pathophysiology of inflammatory bowel disease: an overview. The Surgical clinics of North America. 2007;87(3):575-85.

37. Xu XR, Liu CQ, Feng BS, Liu ZJ. Dysregulation of mucosal immune response in pathogenesis of inflammatory bowel disease. World journal of gastroenterology : WJG. 2014;20(12):3255-64.

38. Chiricozzi A, Zhang S, Dattola A, Cannizzaro MV, Gabellini M, Chimenti S, et al. New insights into the pathogenesis of cutaneous autoimmune disorders. Journal of biological regulators and homeostatic agents. 2012;26(2):165-70.

39. Toussirot E. The IL23/Th17 pathway as a therapeutic target in chronic inflammatory diseases. Inflammation \& allergy drug targets. 2012;11(2):159-68.

40. Ng SC, Bernstein CN, Vatn MH, Lakatos PL, Loftus EV, Jr., Tysk C, et al. Geographical variability and environmental risk factors in inflammatory bowel disease. Gut. 2013;62(4):630-49.

41. Ko JK, Auyeung KK. Inflammatory bowel disease: etiology, pathogenesis and current therapy. Current pharmaceutical design. 2014;20(7):1082-96.

42. Veloso FT. Extraintestinal manifestations of inflammatory bowel disease: do they influence treatment and outcome? World journal of gastroenterology : WJG. 2011;17(22):2702-7.

43. Larsen S, Bendtzen $\mathrm{K}$, Nielsen $\mathrm{OH}$. Extraintestinal manifestations of inflammatory bowel disease: epidemiology, diagnosis, and management. Annals of medicine. 2010;42(2):97-114.

44. Skroza N, Proietti I, Pampena R, La Viola G, Bernardini N, Nicolucci F, et al. Correlations between psoriasis and inflammatory bowel diseases. BioMed research international. 2013;2013:983902.

45. Navaneethan U, Shen B. Hepatopancreatobiliary manifestations and complications associated with inflammatory bowel disease. Inflammatory bowel diseases. 2010;16(9):1598-619.

46. Rothfuss KS, Stange EF, Herrlinger KR. Extraintestinal manifestations and complications in inflammatory bowel diseases. World journal of gastroenterology : WJG. 2006;12(30):4819-31.

47. Magro F, Langner C, Driessen A, Ensari A, Geboes K, Mantzaris GJ, et al. European consensus on the histopathology of inflammatory bowel disease. Journal of Crohn's \& colitis. 2013;7(10):827-51.

48. Vilela EG, Torres HO, Martins FP, Ferrari Mde L, Andrade MM, Cunha AS. Evaluation of inflammatory activity in Crohn's disease and ulcerative colitis. World journal of gastroenterology : WJG. 2012;18(9):872-81.

49. Niv Y. Capsule endoscopy in the diagnosis of Crohn's disease. Medical devices (Auckland, NZ). 2013;6:85-9.

50. Yamagami H, Watanabe K, Kamata N, Sogawa M, Arakawa T. Small bowel endoscopy in inflammatory bowel disease. Clinical endoscopy. 2013;46(4):321-6.

51. Fallis SA, Murphy P, Sinha R, Hawker P, Gladman L, Busby K, et al. Magnetic resonance enterography in Crohn's disease: a comparison with the findings at surgery. Colorectal disease : the official journal of the Association of Coloproctology of Great Britain and Ireland. 2013;15(10):1273-80. 
52. Lee SD, Cohen RD. Endoscopy of the small bowel in inflammatory bowel disease. Gastrointestinal endoscopy clinics of North America. 2002;12(3):485-93.

53. Park MJ, Lim JS. Computed tomography enterography for evaluation of inflammatory bowel disease. Clinical endoscopy. 2013;46(4):327-66.

54. Raman SP, Horton KM, Fishman EK. Computed tomography of Crohn's disease: The role of three dimensional technique. World journal of radiology. 2013;5(5):193-201.

55. Lew RJ, Ginsberg GG. The role of endoscopic ultrasound in inflammatory bowel disease. Gastrointestinal endoscopy clinics of North America. 2002;12(3):561-71.

56. Gramlich T, Petras RE. Pathology of inflammatory bowel disease. Seminars in pediatric surgery. 2007;16(3):154-63.

57. Yantiss RK, Odze RD. Diagnostic difficulties in inflammatory bowel disease pathology. Histopathology. 2006;48(2):116-32.

58. Price AB, Morson BC. Inflammatory bowel disease: the surgical pathology of Crohn's disease and ulcerative colitis. Human pathology. 1975;6(1):7-29.

59. Parkes M, Jewell DP. Review article: the management of severe Crohn's disease. Alimentary pharmacology \& therapeutics. 2001;15(5):563-73.

60. Shaffer VO, Wexner SD. Surgical management of Crohn's disease. Langenbeck's archives of surgery / Deutsche Gesellschaft fur Chirurgie. 2013;398(1):13-27.

61. Hanauer SB. Review article: evolving concepts in treatment and disease modification in ulcerative colitis. Alimentary pharmacology \& therapeutics. 2008;27 Suppl 1:15-21.

62. Rogler G. Medical management of ulcerative colitis. Digestive diseases (Basel, Switzerland). 2009;27(4):542-9.

63. Ordas I, Eckmann L, Talamini M, Baumgart DC, Sandborn WJ. Ulcerative colitis. Lancet. 2012;380(9853):1606-19.

64. Lissner D, Siegmund B. Ulcerative colitis: current and future treatment strategies. Digestive diseases (Basel, Switzerland). 2013;31(1):91-4.

65. Grucela A, Steinhagen RM. Current surgical management of ulcerative colitis. The Mount Sinai journal of medicine, New York. 2009;76(6):606-12.

66. Loftus EV, Jr., Schoenfeld P, Sandborn WJ. The epidemiology and natural history of Crohn's disease in population-based patient cohorts from North America: a systematic review. Alimentary pharmacology \& therapeutics. 2002;16(1):51-60.

67. Salek H, Balouch A, Sedghizadeh PP. Oral manifestation of Crohn's disease without concomitant gastrointestinal involvement. Odontology / the Society of the Nippon Dental University. 2013.

68. Zbar AP, Ben-Horin S, Beer-Gabel M, Eliakim R. Oral Crohn's disease: is it a separable disease from orofacial granulomatosis? A review. Journal of Crohn's \& colitis. 2012;6(2):135-42.

69. Sanderson J, Nunes C, Escudier M, Barnard K, Shirlaw P, Odell E, et al. Orofacial granulomatosis: Crohn's disease or a new inflammatory bowel disease? Inflammatory bowel diseases. 2005;11(9):840-6.

70. Nico MM, Hussein TP, Aoki V, Lourenco SV. Pyostomatitis vegetans and its relation to inflammatory bowel disease, pyoderma gangrenosum, pyodermatitis vegetans, and pemphigus. Journal of oral pathology \& medicine : official publication of the 
International Association of Oral Pathologists and the American Academy of Oral Pathology. 2012;41(8):584-8.

71. Hegarty AM, Barrett AW, Scully C. Pyostomatitis vegetans. Clinical and experimental dermatology. 2004;29(1):1-7.

72. Jose FA, Garnett EA, Vittinghoff E, Ferry GD, Winter HS, Baldassano RN, et al. Development of extraintestinal manifestations in pediatric patients with inflammatory bowel disease. Inflammatory bowel diseases. 2009;15(1):63-8.

73. Frankel DH, Mostofi RS, Lorincz AL. Oral Crohn's disease: report of two cases in brothers with metallic dysgeusia and a review of the literature. Journal of the American Academy of Dermatology. 1985;12(2 Pt 1):260-8.

74. Huber MA. Gastrointestinal illnesses and their effects on the oral cavity. Oral and maxillofacial surgery clinics of North America. 2008;20(4):625-34.

75. Katz J, Shenkman A, Stavropoulos F, Melzer E. Oral signs and symptoms in relation to disease activity and site of involvement in patients with inflammatory bowel disease. Oral diseases. 2003;9(1):34-40.

76. Dupuy A, Cosnes J, Revuz J, Delchier JC, Gendre JP, Cosnes A. Oral Crohn disease: clinical characteristics and long-term follow-up of 9 cases. Archives of dermatology. 1999;135(4):439-42.

77. Hussey S, Fleming P, Rowland M, Harty S, Chan L, Broderick A, et al. Disease outcome for children who present with oral manifestations of Crohn's disease. European archives of paediatric dentistry : official journal of the European Academy of Paediatric Dentistry. 2011;12(3):167-9. 


\title{
Appendix A: Raw Data Tables
}

\section{Table 1: Frequency of oral lesions in normal control and IBD patients}

\author{
$\mathrm{DX}=$ Diagnosis, $\mathrm{PV}=$ Pyostomatitis vegetans, $\mathrm{LU}=$ Linear ulceration, $\mathrm{MS}=\mathrm{Mucosal}$
}

swelling, $\mathrm{C}=$ Cobblestoning, $\mathrm{GH}=$ Gingival hyperplasia, $\mathrm{P}=$ Prevalence

\begin{tabular}{|c|c|c|c|c|c|c|c|c|c|c|c|c|c|c|c|c|c|c|c|}
\hline Obs & SUB & SEX & RACE & AGE & GROUP & DX & PVL L & & MS & C & GH & TOTAL & PPV & PLU & PGH & PMS & PC & PAL & DECADE \\
\hline 1 & 1 & $\mathbf{F}$ & C & 19 & $\mathbf{N}$ & None & 0 & 0 & 0 & 0 & 0 & 0 & 0 & 0 & 0 & 0 & 0 & 0 & 2 \\
\hline 2 & 2 & $\mathbf{F}$ & C & 57 & $\mathbf{N}$ & None & 0 & 0 & \begin{tabular}{l|l}
0 \\
\end{tabular} & 0 & 0 & 0 & 0 & 0 & 0 & 0 & 0 & 0 & 6 \\
\hline 3 & 3 & F & AA & 58 & $\mathrm{~N}$ & None & 0 & 0 & 0 & 0 & 0 & 0 & 0 & 0 & 0 & 0 & 0 & 0 & 6 \\
\hline 4 & 4 & M & C & 58 & $\mathbf{N}$ & None & 0 & 0 & 0 & 0 & 0 & 0 & 0 & 0 & 0 & 0 & 0 & 0 & 6 \\
\hline 5 & 5 & $M$ & C & 67 & $\mathrm{~N}$ & None & 0 & 0 & 0 & 0 & 0 & 0 & 0 & 0 & 0 & 0 & 0 & 0 & 7 \\
\hline 6 & 6 & M & C & 46 & $\mathbf{N}$ & None & 0 & 0 & 0 & 0 & 0 & 0 & 0 & 0 & 0 & 0 & 0 & 0 & 5 \\
\hline 7 & 7 & $M$ & C & 25 & $\mathrm{~N}$ & None & 0 & 0 & 0 & 0 & 0 & 0 & 0 & 0 & 0 & 0 & 0 & 0 & 3 \\
\hline 8 & 8 & $\mathbf{F}$ & C & 85 & $\mathbf{N}$ & None & 0 & 0 & 0 & 0 & 0 & 0 & 0 & 0 & 0 & 0 & 0 & 0 & 9 \\
\hline 9 & 9 & F & C & 61 & $\mathbf{N}$ & None & 0 & 0 & \begin{tabular}{l|l}
0 \\
\end{tabular} & 0 & 0 & 0 & 0 & 0 & 0 & 0 & 0 & 0 & 7 \\
\hline 10 & 10 & $\mathbf{F}$ & C & 31 & $\mathbf{N}$ & None & 0 & 0 & 0 & 0 & 0 & 0 & 0 & 0 & 0 & 0 & 0 & 0 & 4 \\
\hline 11 & 11 & M & C & 59 & $\mathbf{N}$ & None & 0 & 0 & 0 & 0 & 0 & 0 & 0 & 0 & 0 & 0 & 0 & 0 & 6 \\
\hline 12 & 12 & M & C & 35 & $\mathbf{N}$ & None & 0 & 0 & 0 & 0 & 0 & 0 & 0 & 0 & 0 & 0 & 0 & 0 & 4 \\
\hline 13 & 13 & $M$ & C & 31 & $N$ & None & 0 & 0 & 0 & 0 & 0 & 0 & 0 & 0 & 0 & 0 & 0 & 0 & 4 \\
\hline 14 & 14 & $F$ & C & 20 & $\mathbf{N}$ & None & 0 & 0 & 0 & 0 & 0 & 0 & 0 & 0 & 0 & 0 & 0 & 0 & 2 \\
\hline 15 & 15 & $F$ & AA & 48 & $\mathrm{~N}$ & None & 0 & 0 & 0 & 0 & 0 & 0 & 0 & 0 & 0 & 0 & 0 & 0 & 5 \\
\hline 16 & 16 & $\mathbf{F}$ & C & 42 & $\mathbf{N}$ & None & 0 & 0 & 0 & 0 & 0 & 0 & 0 & 0 & 0 & 0 & 0 & 0 & 5 \\
\hline 17 & 17 & F & C & 25 & $\mathrm{~N}$ & None & 0 & 0 & 0 & 0 & 0 & 0 & 0 & 0 & 0 & 0 & 0 & 0 & 3 \\
\hline 18 & 18 & $\mathbf{F}$ & C & 48 & $\mathbf{N}$ & None & 0 & 0 & 0 & 0 & 0 & 0 & 0 & 0 & 0 & 0 & 0 & 0 & 5 \\
\hline 19 & 19 & $F$ & C & 58 & $\mathrm{~N}$ & None & 0 & 0 & 0 & 0 & 0 & 0 & 0 & 0 & 0 & 0 & 0 & 0 & 6 \\
\hline 20 & 20 & M & C & 34 & $\mathbf{N}$ & None & 0 & 0 & 0 & 0 & 0 & 0 & 0 & 0 & 0 & 0 & 0 & 0 & 4 \\
\hline 21 & 21 & F & C & 25 & $N$ & None & 0 & 0 & 0 & 0 & 0 & 0 & 0 & 0 & 0 & 0 & 0 & 0 & 3 \\
\hline 22 & 22 & $\mathbf{F}$ & C & 72 & $\mathbf{N}$ & None & 0 & 0 & 0 & 0 & 0 & 0 & 0 & 0 & 0 & 0 & 0 & 0 & 8 \\
\hline 23 & 23 & $F$ & C & 24 & $\mathrm{~N}$ & None & 0 & 0 & \begin{tabular}{l|l}
0 \\
\end{tabular} & 0 & 0 & 0 & 0 & 0 & 0 & 0 & 0 & 0 & 3 \\
\hline 24 & 24 & $\mathbf{F}$ & C & 27 & $\mathbf{N}$ & None & 0 & 0 & 0 & 0 & 0 & 0 & 0 & 0 & 0 & 0 & 0 & 0 & 3 \\
\hline 25 & 25 & F & C & 46 & $\mathrm{~N}$ & None & 0 & 0 & 0 & 0 & 0 & 0 & 0 & 0 & 0 & 0 & 0 & 0 & 5 \\
\hline 26 & 26 & $\mathbf{F}$ & C & 25 & $\mathbf{N}$ & None & 0 & 0 & 0 & 0 & 0 & 0 & 0 & 0 & 0 & 0 & 0 & 0 & 3 \\
\hline 27 & 27 & $F$ & C & 24 & $\mathrm{~N}$ & None & 0 & 0 & \begin{tabular}{l|l}
0 \\
\end{tabular} & 0 & 0 & 0 & 0 & 0 & 0 & 0 & 0 & 0 & 3 \\
\hline 28 & 28 & $M$ & C & 52 & $\mathbf{N}$ & None & 0 & 0 & 0 & 0 & 0 & 0 & 0 & 0 & 0 & 0 & 0 & 0 & 6 \\
\hline 29 & 29 & $F$ & C & 71 & $\mathrm{~N}$ & None & 0 & 0 & \begin{tabular}{l|l}
0 & \\
\end{tabular} & 0 & 0 & 0 & 0 & 0 & 0 & 0 & 0 & 0 & 8 \\
\hline 30 & 30 & $\mathbf{F}$ & C & 26 & $\mathbf{N}$ & None & 0 & 0 & 0 & 0 & 0 & 0 & 0 & 0 & 0 & 0 & 0 & 0 & 3 \\
\hline 31 & 31 & $F$ & C & 34 & $\mathrm{~N}$ & None & 0 & 0 & \begin{tabular}{l|l}
0 \\
\end{tabular} & 0 & 0 & 0 & 0 & 0 & $\begin{array}{l}0 \\
\end{array}$ & 0 & 0 & 0 & 4 \\
\hline 32 & 32 & $M$ & C & 34 & $\mathbf{N}$ & None & 0 & 0 & 0 & 0 & 0 & 0 & 0 & 0 & 0 & 0 & 0 & 0 & 4 \\
\hline 33 & 33 & $F$ & C & 26 & $\mathrm{~N}$ & None & 0 & 0 & \begin{tabular}{l|l}
0 &
\end{tabular} & 0 & 0 & 0 & 0 & 0 & 0 & 0 & 0 & 0 & 3 \\
\hline 34 & 34 & F & AA & 18 & $\mathrm{~N}$ & None & 0 & 0 & 0 & 0 & 0 & 0 & 0 & 0 & 0 & 0 & 0 & 0 & 2 \\
\hline 35 & 35 & $M$ & C & 51 & $\mathrm{~N}$ & None & 0 & 0 & \begin{tabular}{l|l}
0 \\
\end{tabular} & 0 & 0 & 0 & 0 & 0 & 0 & 0 & 0 & 0 & 6 \\
\hline 36 & 36 & $\mathbf{F}$ & C & 27 & $\mathbf{N}$ & None & 0 & 0 & 0 & 0 & 0 & 0 & 0 & 0 & 0 & 0 & 0 & 0 & 3 \\
\hline 37 & 37 & $F$ & C & 58 & $\mathrm{~N}$ & None & 0 & 0 & \begin{tabular}{l|l}
0 \\
\end{tabular} & 0 & 0 & 0 & 0 & 0 & 0 & 0 & 0 & 0 & 6 \\
\hline 38 & 38 & $F$ & C & 33 & $N$ & None & 0 & 0 & 0 & 0 & 0 & 0 & 0 & 0 & 0 & 0 & 0 & 0 & 4 \\
\hline 39 & 39 & $M$ & C & 35 & $\mathbf{N}$ & None & 0 & 0 & 0 & 0 & 0 & 0 & 0 & 0 & 0 & 0 & 0 & 0 & 4 \\
\hline 40 & 40 & $F$ & C & 51 & $N$ & None & 0 & 0 & 0 & 0 & 0 & 0 & 0 & 0 & 0 & 0 & 0 & 0 & 6 \\
\hline
\end{tabular}

Continued 
Table 1 continued

\begin{tabular}{|c|c|c|c|c|c|c|c|c|c|c|c|c|c|c|c|c|c|c|c|}
\hline 42 & 42 & $M$ & C & 46 & $N$ & None & 0 & 0 & 0 & 0 & 0 & 0 & 0 & 0 & 0 & 0 & 0 & 0 & 5 \\
\hline 43 & 43 & $F$ & C & 48 & $N$ & None & 0 & 0 & 0 & 0 & 0 & 0 & 0 & 0 & 0 & 0 & 0 & 0 & 5 \\
\hline 44 & 44 & $F$ & C & 31 & $\mathrm{~N}$ & None & 0 & 0 & 0 & 0 & 0 & 0 & 0 & 0 & 0 & 0 & 0 & 0 & 4 \\
\hline 45 & 45 & $F$ & AA & 49 & N & None & 0 & 0 & 0 & 0 & 0 & 0 & 0 & 0 & 0 & 0 & 0 & 0 & 5 \\
\hline 46 & 46 & $F$ & C & 24 & $N$ & None & 0 & 0 & 0 & 0 & 0 & 0 & 0 & 0 & 0 & 0 & 0 & 0 & 3 \\
\hline 47 & 47 & $\mathrm{~F}$ & C & 64 & $N$ & None & 0 & 0 & 0 & 0 & 0 & 0 & 0 & 0 & 0 & 0 & 0 & 0 & 7 \\
\hline 48 & 48 & M & C & 27 & $N$ & None & 0 & 0 & 0 & 0 & 0 & 0 & 0 & 0 & 0 & 0 & 0 & 0 & 3 \\
\hline 49 & 49 & $F$ & C & 21 & $\mathrm{~N}$ & None & 0 & 0 & 0 & 0 & 0 & 0 & 0 & 0 & 0 & 0 & 0 & 0 & 3 \\
\hline 50 & 50 & $F$ & AA & 45 & $N$ & None & 0 & 0 & 0 & 0 & 0 & 0 & 0 & 0 & 0 & 0 & 0 & 0 & 5 \\
\hline 51 & 51 & $M$ & C & 57 & $N$ & None & 0 & 0 & 0 & 0 & 0 & 0 & 0 & 0 & 0 & 0 & 0 & 0 & 6 \\
\hline 52 & 52 & $F$ & C & 50 & $N$ & None & 0 & 0 & 0 & 0 & 0 & 0 & 0 & 0 & 0 & 0 & 0 & 0 & 5 \\
\hline 53 & 53 & $F$ & C & 25 & $N$ & None & 0 & 0 & 0 & 0 & 0 & 0 & 0 & 0 & 0 & 0 & 0 & 0 & 3 \\
\hline 54 & 54 & $F$ & C & 45 & $N$ & None & 0 & 0 & 0 & 0 & 0 & 0 & 0 & 0 & 0 & 0 & 0 & 0 & 5 \\
\hline 55 & 55 & $F$ & C & 62 & $N$ & None & 0 & 0 & 0 & 0 & 0 & 0 & 0 & 0 & 0 & 0 & 0 & 0 & 7 \\
\hline 56 & 56 & $F$ & C & 31 & $N$ & None & 0 & 0 & 0 & 0 & 0 & 0 & 0 & 0 & 0 & 0 & 0 & 0 & 4 \\
\hline 57 & 57 & $F$ & C & 18 & $\mathrm{~N}$ & None & 0 & 0 & 0 & 0 & 0 & 0 & 0 & 0 & 0 & 0 & 0 & 0 & 2 \\
\hline 58 & 58 & $F$ & C & 27 & $N$ & None & 0 & 0 & 0 & 0 & 0 & 0 & 0 & 0 & 0 & 0 & 0 & 0 & 3 \\
\hline 59 & 59 & $M$ & C & 20 & $N$ & None & 0 & 0 & 0 & 0 & 0 & 0 & 0 & 0 & 0 & 0 & 0 & 0 & 2 \\
\hline 60 & 60 & $\mathrm{~F}$ & C & 27 & $N$ & None & 0 & 0 & 0 & 0 & 0 & 0 & 0 & 0 & 0 & 0 & 0 & 0 & 3 \\
\hline 61 & 61 & $F$ & C & 21 & $N$ & None & 0 & 0 & 0 & 0 & 0 & 0 & 0 & 0 & 0 & 0 & 0 & 0 & 3 \\
\hline 62 & 62 & $M$ & C & 42 & $\mathrm{~N}$ & None & 0 & 0 & 0 & 0 & 0 & 0 & 0 & 0 & 0 & 0 & 0 & 0 & 5 \\
\hline 63 & 63 & $M$ & C & 24 & $N$ & None & 0 & 0 & 0 & 0 & 0 & 0 & 0 & 0 & 0 & 0 & 0 & 0 & 3 \\
\hline 64 & 64 & $\mathrm{~F}$ & C & 61 & $N$ & None & 0 & 0 & 0 & 0 & 0 & 0 & 0 & 0 & 0 & 0 & 0 & 0 & 7 \\
\hline 65 & 65 & $F$ & C & 26 & $N$ & None & 0 & 0 & 0 & 0 & 0 & 0 & 0 & 0 & 0 & 0 & 0 & 0 & 3 \\
\hline 66 & 66 & $M$ & C & 28 & $N$ & None & 0 & 0 & 0 & 0 & 0 & 0 & 0 & 0 & 0 & 0 & 0 & 0 & 3 \\
\hline 67 & 67 & $F$ & C & 57 & $N$ & None & 0 & 0 & 0 & 0 & 0 & 0 & 0 & 0 & 0 & 0 & 0 & 0 & 6 \\
\hline 68 & 68 & $F$ & AA & 44 & $N$ & None & 0 & 0 & 0 & 0 & 0 & 0 & 0 & 0 & 0 & 0 & 0 & 0 & 5 \\
\hline 69 & 69 & $M$ & C & 63 & $N$ & None & 0 & 0 & 0 & 0 & 0 & 0 & 0 & 0 & 0 & 0 & 0 & 0 & 7 \\
\hline 70 & 70 & $F$ & C & 48 & $N$ & None & 0 & 0 & 0 & 0 & 0 & 0 & 0 & 0 & 0 & 0 & 0 & 0 & 5 \\
\hline 71 & 71 & $M$ & C & 36 & $N$ & None & 0 & 0 & 0 & 0 & 0 & 0 & 0 & 0 & 0 & 0 & 0 & 0 & 4 \\
\hline 72 & 72 & $M$ & C & 22 & $N$ & None & 0 & 0 & 0 & 0 & 0 & 0 & 0 & 0 & 0 & 0 & 0 & 0 & 3 \\
\hline 73 & 73 & $F$ & AA & 25 & $N$ & None & 0 & 0 & 0 & 0 & 0 & 0 & 0 & 0 & 0 & 0 & 0 & 0 & 3 \\
\hline 74 & 74 & $F$ & C & 62 & $N$ & None & 0 & 0 & 0 & 0 & 0 & 0 & 0 & 0 & 0 & 0 & 0 & 0 & 7 \\
\hline 75 & 75 & $F$ & C & 58 & $N$ & None & 0 & 0 & 0 & 0 & 0 & 0 & 0 & 0 & 0 & 0 & 0 & 0 & 6 \\
\hline 76 & 76 & $M$ & C & 49 & $N$ & None & 0 & 0 & 0 & 0 & 0 & 0 & 0 & 0 & 0 & 0 & 0 & 0 & 5 \\
\hline 77 & 77 & $F$ & C & 32 & $N$ & None & 0 & 0 & 0 & 0 & 0 & 0 & 0 & 0 & 0 & 0 & 0 & 0 & 4 \\
\hline 78 & 78 & $M$ & C & 60 & $N$ & None & 0 & 0 & 0 & 0 & 0 & 0 & 0 & 0 & 0 & 0 & 0 & 0 & 6 \\
\hline 79 & 79 & $M$ & C & 69 & $N$ & None & 0 & 0 & 0 & 0 & 0 & 0 & 0 & 0 & 0 & 0 & 0 & 0 & 7 \\
\hline 80 & 80 & $F$ & C & 38 & $N$ & None & 0 & 0 & 0 & 0 & 0 & 0 & 0 & 0 & 0 & 0 & 0 & 0 & 4 \\
\hline
\end{tabular}

Continued 
Table 1 Continued

\begin{tabular}{|c|c|c|c|c|c|c|c|c|c|c|c|c|c|c|c|c|c|c|c|}
\hline 81 & 81 & & C & 25 & $\mathbf{N}$ & None & 0 & 0 & 0 & 0 & 0 & 0 & 0 & 0 & 0 & 0 & 0 & 0 & 3 \\
\hline 82 & 82 & $M$ & C & 31 & $N$ & None & 0 & 0 & 0 & 0 & 0 & 0 & 0 & 0 & 0 & 0 & 0 & 0 & 4 \\
\hline 83 & 83 & $M$ & C & 59 & $\mathbf{N}$ & None & 0 & 0 & 0 & 0 & 0 & 0 & 0 & 0 & 0 & 0 & 0 & 0 & 6 \\
\hline 84 & 84 & $F$ & C & 26 & $N$ & None & 0 & 0 & 0 & 0 & 0 & 0 & 0 & 0 & 0 & 0 & 0 & 0 & 3 \\
\hline 85 & 85 & $F$ & C & 18 & $\mathbf{N}$ & None & 0 & 0 & 0 & 0 & 0 & 0 & 0 & 0 & 0 & 0 & 0 & 0 & 2 \\
\hline 86 & 86 & $M$ & C & 54 & $N$ & None & 0 & 0 & 0 & 0 & 0 & 0 & 0 & 0 & 0 & 0 & 0 & 0 & 6 \\
\hline 87 & 87 & $M$ & C & 34 & $\mathbf{N}$ & None & 0 & 0 & 0 & 0 & 0 & 0 & 0 & 0 & 0 & 0 & 0 & 0 & 4 \\
\hline 88 & 88 & $F$ & C & 25 & $N$ & None & 0 & 0 & 0 & 0 & 0 & 0 & 0 & 0 & 0 & 0 & 0 & 0 & 3 \\
\hline 89 & 89 & $F$ & C & 59 & $\mathbf{N}$ & None & 0 & 0 & 0 & 0 & 0 & 0 & 0 & 0 & 0 & 0 & 0 & 0 & 6 \\
\hline 90 & 90 & $F$ & C & 40 & $\mathbf{N}$ & None & 0 & 0 & 0 & 0 & 0 & 0 & 0 & 0 & 0 & 0 & 0 & 0 & 4 \\
\hline 91 & 91 & $M$ & C & 50 & $\mathbf{N}$ & None & 0 & 0 & 0 & 0 & 0 & 0 & 0 & 0 & 0 & 0 & 0 & 0 & 5 \\
\hline 92 & 92 & $M$ & C & 60 & $\mathbf{N}$ & None & 0 & 0 & 0 & 0 & 0 & 0 & 0 & 0 & 0 & 0 & 0 & 0 & 6 \\
\hline 93 & 93 & M & C & 55 & $\mathbf{N}$ & None & 0 & 0 & 0 & 0 & 0 & 0 & 0 & 0 & 0 & 0 & 0 & 0 & 6 \\
\hline 94 & 94 & $F$ & C & 47 & $\mathbf{N}$ & None & 0 & 0 & 0 & 0 & 0 & 0 & 0 & 0 & 0 & 0 & 0 & 0 & 5 \\
\hline 95 & 95 & M & A & 21 & $\mathbf{N}$ & None & 0 & 0 & 0 & 0 & 0 & 0 & 0 & 0 & 0 & 0 & 0 & 0 & 3 \\
\hline 96 & 96 & $F$ & C & 49 & $\mathbf{N}$ & None & 0 & 0 & 0 & 0 & 0 & 0 & 0 & 0 & 0 & 0 & 0 & 0 & 5 \\
\hline 97 & 97 & $F$ & C & 48 & $\mathbf{N}$ & None & 0 & 0 & 0 & 0 & 0 & 0 & 0 & 0 & 0 & 0 & 0 & 0 & 5 \\
\hline 98 & 98 & M & C & 64 & $\mathbf{N}$ & None & 0 & 0 & 0 & 0 & 0 & 0 & 0 & 0 & 0 & 0 & 0 & 0 & 7 \\
\hline 99 & 99 & $M$ & C & 35 & $N$ & None & 0 & 0 & 0 & 0 & 0 & 0 & 0 & 0 & 0 & 0 & 0 & 0 & 4 \\
\hline 100 & 100 & $\mathbf{F}$ & C & 35 & $\mathbf{N}$ & None & 0 & 0 & 0 & 0 & 0 & 0 & 0 & 0 & 0 & 0 & 0 & 0 & 4 \\
\hline 101 & 1000 & $M$ & A & 22 & IBD & UC & 0 & 0 & 0 & 0 & 0 & 0 & 0 & 0 & 0 & 0 & 0 & 0 & 3 \\
\hline 102 & 2000 & $F$ & C & 50 & IBD & $C D$ & 0 & 0 & 0 & 0 & 0 & 0 & 0 & 0 & 0 & 0 & 0 & 0 & 5 \\
\hline 103 & 3000 & $F$ & C & 21 & IBD & UC & 0 & 0 & 0 & 0 & 0 & 0 & 0 & 0 & 0 & 0 & 0 & 0 & 3 \\
\hline 104 & 4000 & $M$ & C & 65 & IBD & CD & 0 & 0 & 0 & 0 & 0 & 0 & 0 & 0 & 0 & 0 & 0 & 0 & 7 \\
\hline 105 & 5000 & $F$ & C & 38 & IBD & $C D$ & 0 & 0 & 0 & 0 & 0 & 0 & 0 & 0 & 0 & 0 & 0 & 0 & 4 \\
\hline 106 & 6000 & $F$ & C & 50 & IBD & CD & 0 & 0 & 0 & 0 & 0 & 0 & 0 & 0 & 0 & 0 & 0 & 0 & 5 \\
\hline 107 & 7000 & $M$ & C & 31 & IBD & CD & 0 & 0 & 0 & 0 & 0 & 0 & 0 & 0 & 0 & 0 & 0 & 0 & 4 \\
\hline 108 & 8000 & M & C & 53 & IBD & UC & 0 & 0 & 0 & 0 & 0 & 0 & 0 & 0 & 0 & 0 & 0 & 0 & 6 \\
\hline 109 & 9000 & $F$ & C & 47 & IBD & $C D$ & 0 & 0 & 0 & 0 & 0 & 0 & 0 & 0 & 0 & 0 & 0 & 0 & 5 \\
\hline 110 & 10000 & $F$ & C & 56 & IBD & CD & 0 & 0 & 0 & 0 & 0 & 0 & 0 & 0 & 0 & 0 & 0 & 0 & 6 \\
\hline 111 & 11000 & $F$ & C & 27 & IBD & $C D$ & 0 & 0 & 0 & 0 & 0 & 0 & 0 & 0 & 0 & 0 & 0 & 0 & 3 \\
\hline 112 & 12000 & M & C & 22 & IBD & CD & 0 & 0 & 0 & 0 & 0 & 0 & 0 & 0 & 0 & 0 & 0 & 0 & 3 \\
\hline 113 & 13000 & $F$ & C & 33 & IBD & CD & 0 & 0 & 0 & 0 & 0 & 0 & 0 & 0 & 0 & 0 & 0 & 0 & 4 \\
\hline 114 & 14000 & $M$ & C & 64 & IBD & CD & 0 & 0 & 0 & 0 & 0 & 0 & 0 & 0 & 0 & 0 & 0 & 0 & 7 \\
\hline 115 & 15000 & $M$ & C & 58 & IBD & $C D$ & 0 & 0 & 0 & 0 & 0 & 0 & 0 & 0 & 0 & 0 & 0 & 0 & 6 \\
\hline 116 & 16000 & $F$ & C & 19 & IBD & CD & 0 & 0 & 0 & 0 & 0 & 0 & 0 & 0 & 0 & 0 & 0 & 0 & 2 \\
\hline 117 & 17000 & M & C & 29 & IBD & CD & 0 & 0 & 0 & 0 & 0 & 0 & 0 & 0 & 0 & 0 & 0 & 0 & 3 \\
\hline 118 & 18000 & $M$ & C & 18 & IBD & CD & 0 & 0 & 0 & 0 & 0 & 0 & 0 & 0 & 0 & 0 & 0 & 0 & 2 \\
\hline 119 & 19000 & $F$ & C & 35 & IBD & CD & 0 & 0 & 0 & 0 & 0 & 0 & 0 & 0 & 0 & 0 & 0 & 0 & 4 \\
\hline 120 & 20000 & & C & 25 & IBD & UC & 0 & 0 & 0 & 0 & 0 & 0 & 0 & 0 & 0 & 0 & 0 & 0 & 3 \\
\hline
\end{tabular}

Continued 
Table 1 continued

\begin{tabular}{|c|c|c|c|c|c|c|c|c|c|c|c|c|c|c|c|c|c|c|c|}
\hline 121 & 21000 & $M$ & C & & IBD & CD & 0 & 0 & 0 & 0 & 0 & 0 & 0 & 0 & 0 & 0 & 0 & 0 & 4 \\
\hline 122 & 22000 & $F$ & C & 29 & IBD & $C D$ & 0 & 0 & 0 & 0 & 0 & 0 & 0 & 0 & 0 & 0 & 0 & 0 & 3 \\
\hline 123 & 23000 & $F$ & C & 44 & IBD & $C D$ & 0 & 0 & 0 & 0 & 0 & 0 & 0 & 0 & 0 & 0 & 0 & 0 & 5 \\
\hline 124 & 424000 & $F$ & C & 33 & IBD & CD & 0 & 0 & 0 & 0 & 0 & 0 & 0 & 0 & 0 & 0 & 0 & 0 & 4 \\
\hline 125 & 25000 & $M$ & C & 48 & IBD & CD & 0 & 0 & 0 & 0 & 0 & 0 & 0 & 0 & 0 & 0 & 0 & 0 & 5 \\
\hline 126 & 26000 & $F$ & C & 25 & IBD & $C D$ & 0 & 0 & 0 & 0 & 0 & 0 & 0 & 0 & 0 & 0 & 0 & 0 & 3 \\
\hline 127 & 27000 & $F$ & C & 26 & IBD & $C D$ & 0 & 0 & 0 & 0 & 0 & 0 & 0 & 0 & 0 & 0 & 0 & 0 & 3 \\
\hline 128 & 328000 & $F$ & C & 52 & IBD & CD & 0 & 0 & 0 & 0 & 0 & 0 & 0 & 0 & 0 & 0 & 0 & 0 & 6 \\
\hline 129 & 29000 & $M$ & C & 27 & IBD & UC & 0 & 0 & 0 & 0 & 0 & 0 & 0 & 0 & 0 & 0 & 0 & 0 & 3 \\
\hline 130 & 30000 & $F$ & C & 51 & IBD & $C D$ & 0 & 0 & 0 & 0 & 0 & 0 & 0 & 0 & 0 & 0 & 0 & 0 & 6 \\
\hline 131 & 31000 & $M$ & C & 20 & IBD & CD & 0 & 0 & 0 & 0 & 0 & 0 & 0 & 0 & 0 & 0 & 0 & 0 & 2 \\
\hline 132 & 32000 & $F$ & C & 39 & IBD & $C D$ & 0 & 0 & 0 & 0 & 0 & 0 & 0 & 0 & 0 & 0 & 0 & 0 & 4 \\
\hline 133 & 33000 & $F$ & C & 37 & IBD & CD & 0 & 0 & 0 & 0 & 0 & 0 & 0 & 0 & 0 & 0 & 0 & 0 & 4 \\
\hline 134 & \begin{tabular}{|l|l|} 
\\
\end{tabular} & $M$ & C & 33 & IBD & CD & 0 & 0 & 0 & 0 & 0 & 0 & 0 & 0 & 0 & 0 & 0 & 0 & 4 \\
\hline 135 & 35000 & $F$ & C & 31 & IBD & $C D$ & 0 & 0 & 0 & 0 & 0 & 0 & 0 & 0 & 0 & 0 & 0 & 0 & 4 \\
\hline 136 & $5 \mid 36000$ & $M$ & C & 22 & IBD & UC & 0 & 0 & 0 & 0 & 0 & 0 & 0 & 0 & 0 & 0 & 0 & 0 & 3 \\
\hline 137 & 37000 & $F$ & C & 23 & IBD & UC & 0 & 0 & 0 & 0 & 0 & 0 & 0 & 0 & 0 & 0 & 0 & 0 & 3 \\
\hline 138 & 38000 & $F$ & C & 28 & IBD & UC & 0 & 0 & 0 & 0 & 0 & 0 & 0 & 0 & 0 & 0 & 0 & 0 & 3 \\
\hline 139 & \begin{tabular}{|l|l|}
39000 \\
\end{tabular} & $M$ & C & 56 & IBD & UC & 0 & 0 & 0 & 0 & 0 & 0 & 0 & 0 & 0 & 0 & 0 & 0 & 6 \\
\hline 140 & 40000 & $M$ & C & 67 & IBD & $C D$ & 0 & 0 & 0 & 0 & 0 & 0 & 0 & 0 & 0 & 0 & 0 & 0 & 7 \\
\hline 141 & 4 & $M$ & C & 34 & IBD & CD & 0 & 0 & 0 & 0 & 0 & 0 & 0 & 0 & 0 & 0 & 0 & 0 & 4 \\
\hline 142 & 42000 & $F$ & C & 37| & IBD & CD & 0 & 0 & 0 & 0 & 0 & 0 & 0 & 0 & 0 & 0 & 0 & 0 & 4 \\
\hline 143 & \begin{tabular}{|l|l|}
3 \\
\end{tabular} & $M$ & C & 58 & IBD & CD & 0 & 0 & 0 & 0 & 0 & 0 & 0 & 0 & 0 & 0 & 0 & 0 & 6 \\
\hline 144 & 44000 & $M$ & C & 32 & IBD & UC & 0 & 0 & 0 & 0 & 0 & 0 & 0 & 0 & 0 & 0 & 0 & 0 & 3 \\
\hline 145 & 45000 & $F$ & AA & 60 & IBD & CD & 0 & 0 & 0 & 0 & 0 & 0 & 0 & 0 & 0 & 0 & 0 & 0 & 6 \\
\hline 146 & \begin{tabular}{|l|l|}
56000 \\
\end{tabular} & $M$ & C & 22 & IBD & $C D$ & 0 & 0 & 0 & 0 & 0 & 0 & 0 & 0 & 0 & 0 & 0 & 0 & 3 \\
\hline 147 & 74000 & $F$ & C & 20 & IBD & CD & 0 & 0 & 0 & 0 & 0 & 0 & 0 & 0 & 0 & 0 & 0 & 0 & 2 \\
\hline 148 & \begin{tabular}{|l|l|} 
& 48000 \\
\end{tabular} & $F$ & AA & 54 & IBD & CD & 0 & 0 & 0 & 0 & 0 & 0 & 0 & 0 & 0 & 0 & 0 & 0 & 6 \\
\hline 149 & 49000 & $F$ & C & 29 & IBD & CD & 0 & 0 & 0 & 0 & 0 & 0 & 0 & 0 & 0 & 0 & 0 & 0 & 3 \\
\hline 150 & 50000 & $M$ & C & 19 & IBD & UC & 0 & 0 & 0 & 0 & 0 & 0 & 0 & 0 & 0 & 0 & 0 & 0 & 2 \\
\hline 151 & 51000 & $F$ & AA & 19 & IBD & $C D$ & 0 & 0 & 0 & 0 & 0 & 0 & 0 & 0 & 0 & 0 & 0 & 0 & 2 \\
\hline 152 & 52000 & $F$ & AA & 58 & IBD & CD & 0 & 0 & 0 & 0 & 0 & 0 & 0 & 0 & 0 & 0 & 0 & 0 & 5 \\
\hline 153 & \begin{tabular}{|l|l|}
53000 \\
\end{tabular} & $F$ & C & 63 & IBD & $C D$ & 0 & 0 & 0 & 0 & 0 & 0 & 0 & 0 & 0 & 0 & 0 & 0 & 7 \\
\hline 154 & 54000 & $F$ & C & 37 & IBD & $C D$ & 0 & 0 & 0 & 0 & 0 & 0 & 0 & 0 & 0 & 0 & 0 & 0 & 4 \\
\hline 155 & 55000 & $M$ & C & 41 & IBD & UC & 0 & 0 & 0 & 0 & 0 & 0 & 0 & 0 & 0 & 0 & 0 & 0 & 5 \\
\hline 156 & 56000 & $M$ & C & 24 & IBD & CD & 0 & 0 & 0 & 0 & 0 & 0 & 0 & 0 & 0 & 0 & 0 & 0 & 3 \\
\hline 157 & 57000 & $F$ & C & 66 & IBD & $C D$ & 0 & 0 & 0 & 0 & 0 & 0 & 0 & 0 & 0 & 0 & 0 & 0 & 7 \\
\hline 158 & 58000 & $M$ & C & 23 & IBD & UC & 0 & 0 & 0 & 0 & 0 & 0 & 0 & 0 & 0 & 0 & 0 & 0 & 3 \\
\hline 159 & 59000 & $F$ & C & 38 & IBD & $C D$ & 0 & 0 & 0 & 0 & 0 & 0 & 0 & 0 & 0 & 0 & 0 & 0 & 4 \\
\hline 160 & 60000 & & C & 34 & IBD & $C D$ & 0 & 0 & 0 & 0 & 0 & 0 & 0 & 0 & 0 & 0 & 0 & 0 & 4 \\
\hline
\end{tabular}

Continued 
Table 1 continued

\begin{tabular}{|c|c|c|c|c|c|c|c|c|c|c|c|c|c|c|c|c|c|c|c|}
\hline 161 & 61000 & $F$ & AA & & IBD & CD & 0 & 0 & 0 & o & 0 & 0 & 0 & 0 & 0 & 0 & 0 & 0 & 6 \\
\hline 162 & 62000 & $F$ & $C$ & \begin{tabular}{l|l|l}
43 &
\end{tabular} & IBD & $C D$ & 0 & 0 & 0 & 0 & 0 & 0 & 0 & 0 & 0 & 0 & 0 & 0 & 5 \\
\hline 163 & 63000 & $F$ & C & 44 I & IBD & CD & 0 & 0 & 0 & 0 & 0 & 0 & 0 & 0 & 0 & 0 & 0 & 0 & 5 \\
\hline 164 & 64000 & $F$ & C & \begin{tabular}{|l|l|}
56 &
\end{tabular} & IBD & CD & 0 & 0 & 0 & 0 & 0 & 0 & 0 & 0 & 0 & 0 & 0 & 0 & 6 \\
\hline 165 & 65000 & $F$ & C & 24 | & IBD & CD & 0 & 0 & 0 & $\begin{array}{ll}0 \\
\end{array}$ & 0 & 0 & 0 & 0 & 0 & 0 & 0 & 0 & 3 \\
\hline 166 & 66000 & $M$ & C & $24 \mid$ & IBD & CD & 0 & 0 & 0 & 0 & 0 & 0 & 0 & 0 & 0 & 0 & 0 & 0 & 3 \\
\hline 167 & 67000 & $M$ & A & 33 I & IBD & CD & 0 & 0 & 0 & 0 & 0 & 0 & 0 & 0 & 0 & 0 & 0 & 0 & 4 \\
\hline 168 & 68000 & $M$ & AA & 501 & IBD & $C D$ & 0 & 0 & 0 & 0 & 0 & 0 & 0 & 0 & 0 & 0 & 0 & 0 & 5 \\
\hline 169 & 69000 & $M$ & C & $25 \mid$ & IBD & CD & 0 & 0 & 0 & 0 & 0 & 0 & 0 & 0 & 0 & 0 & 0 & 0 & 3 \\
\hline 170 & 70000 & $M$ & C & $\begin{array}{ll}63 & 1\end{array}$ & IBD & CD & 0 & 0 & 0 & 0 & 0 & 0 & 0 & 0 & 0 & 0 & 0 & 0 & 7 \\
\hline 171 & 71000 & $F$ & C & $54 \mid$ & IBD & CD & 0 & 0 & 0 & 0 & 0 & 0 & 0 & 0 & 0 & 0 & 0 & 0 & 6 \\
\hline 172 & 72000 & $F$ & C & $28 \mid$ & IBD & CD & 0 & 0 & 0 & 0 & 0 & 0 & 0 & 0 & 0 & 0 & 0 & 0 & 3 \\
\hline 173 & 73000 & $M$ & C & 291 & IBD & CD & 0 & 0 & 0 & 0 & 0 & 0 & 0 & 0 & 0 & 0 & 0 & 0 & 3 \\
\hline 174 & 74000 & $M$ & C & 67 | & IBD & CD & 0 & 0 & 0 & 0 & 0 & 0 & 0 & 0 & 0 & 0 & 0 & 0 & 7 \\
\hline 175 & 75000 & $M$ & C & 401 & IBD & UC & 0 & 0 & 0 & 0 & 0 & 0 & 0 & 0 & 0 & 0 & 0 & 0 & 4 \\
\hline 176 & 76000 & $F$ & C & 41 & IBD & CD & 0 & 0 & 0 & 0 & 0 & 0 & 0 & 0 & 0 & 0 & 0 & 0 & 5 \\
\hline 177 & 77000 & $F$ & C & $68 \mid$ & IBD & UC & 0 & 0 & 0 & 0 & 0 & 0 & 0 & 0 & 0 & 0 & 0 & 0 & 7 \\
\hline 178 & 78000 & $M$ & C & $68 \mid$ & IBD & CD & 0 & 0 & 0 & 0 & 0 & 0 & 0 & 0 & 0 & 0 & 0 & 0 & 7 \\
\hline 179 & 79000 & $M$ & C & 501 & IBD & CD & 0 & 0 & 0 & 0 & 0 & 0 & 0 & 0 & 0 & 0 & 0 & 0 & 5 \\
\hline 180 & 80000 & $F$ & C & $26 \mid$ & IBD & UC & 0 & 0 & 0 & 0 & 0 & 0 & 0 & 0 & 0 & 0 & 0 & 0 & 3 \\
\hline 181 & 81000 & $F$ & C & 361 & IBD & UC & 0 & 0 & 0 & 0 & 0 & 0 & 0 & 0 & 0 & 0 & 0 & 0 & 4 \\
\hline 182 & 82000 & $F$ & C & 33 | & IBD & CD & 0 & 0 & 0 & 0 & 0 & 0 & 0 & 0 & 0 & 0 & 0 & 0 & 4 \\
\hline 183 & 83000 & $F$ & C & \begin{tabular}{l|l|l|l|l|}
48 &
\end{tabular} & IBD & CD & 0 & 0 & 0 & \begin{tabular}{l|l}
0 \\
\end{tabular} & 0 & 0 & 0 & 0 & 0 & 0 & 0 & 0 & 5 \\
\hline 184 & 84000 & $M$ & C & $21 \mid$ & IBD & UC & 0 & 0 & 0 & \begin{tabular}{l|l}
0 \\
\end{tabular} & 0 & 0 & 0 & 0 & 0 & 0 & 0 & 0 & 3 \\
\hline 185 & 85000 & $F$ & C & 191 & IBD & CD & 0 & 0 & 0 & 0 & 0 & 0 & 0 & 0 & 0 & 0 & 0 & 0 & 2 \\
\hline 186 & 86000 & $F$ & C & 301 & IBD & UC & 0 & 0 & 0 & 0 & 0 & 0 & 0 & 0 & 0 & 0 & 0 & 0 & 3 \\
\hline 187 & 87000 & $M$ & C & $48 \mid$ & IBD & CD & 0 & 0 & 0 & 0 & 0 & 0 & 0 & 0 & 0 & 0 & 0 & 0 & 5 \\
\hline 188 & 88000 & $M$ & C & $71 \mid$ & IBD & CD & 0 & 0 & 0 & 0 & 0 & 0 & 0 & 0 & 0 & 0 & 0 & 0 & 8 \\
\hline 189 & 89000 & $M$ & C & $25 \mid$ & IBD & CD & 0 & 0 & 0 & 0 & 0 & 0 & 0 & 0 & 0 & 0 & 0 & 0 & 3 \\
\hline 190 & 90000 & $M$ & C & $\left.71\right|_{1}$ & IBD & UC & 0 & 0 & 0 & 0 & 0 & 0 & 0 & 0 & 0 & 0 & 0 & 0 & 8 \\
\hline 191 & 91000 & $M$ & C & $33 \mid$ & IBD & CD & 0 & 0 & 0 & 0 & 0 & 0 & 0 & 0 & 0 & 0 & 0 & 0 & 4 \\
\hline 192 & 92000 & $M$ & C & 761 & IBD & CD & 0 & 0 & 0 & 0 & 0 & 0 & 0 & 0 & 0 & 0 & 0 & 0 & 8 \\
\hline 193 & 93000 & $M$ & C & $34 \mid 1$ & IBD & CD & 0 & 0 & 0 & 0 & 0 & 0 & 0 & 0 & 0 & 0 & 0 & 0 & 4 \\
\hline 194 & 94000 & $M$ & C & $33 \mid$ & IBD & UC & 0 & 0 & 0 & 0 & 0 & 0 & 0 & 0 & 0 & 0 & 0 & 0 & 4 \\
\hline 195 & 95000 & $M$ & C & $18 \mid$ & IBD & CD & 0 & 0 & 0 & 0 & 0 & 0 & 0 & 0 & 0 & 0 & 0 & 0 & 2 \\
\hline 196 & 96000 & $F$ & AA & $19 \mid$ & IBD & CD & 0 & 0 & 0 & 0 & 0 & 0 & 0 & 0 & 0 & 0 & 0 & 0 & 2 \\
\hline 197 & 97000 & $\mathbf{M}$ & C & $47 \mid$ & IBD & CD & 0 & 0 & 0 & 0 & 0 & 0 & 0 & 0 & 0 & 0 & 0 & 0 & 5 \\
\hline 198 & 98000 & $F$ & C & $30 \mid$ & IBD & CD & 0 & 0 & 0 & 0 & 0 & 0 & 0 & 0 & 0 & 0 & 0 & 0 & 3 \\
\hline 199 & 99000 & $\mathbf{M}$ & C & $21 \mid$ & IBD & CD & 0 & 0 & 0 & 0 & 0 & 0 & 0 & 0 & 0 & 0 & 0 & 0 & 3 \\
\hline 200 & $1 E+05$ & $F$ & C & | & IBD & $C D$ & 0 & 0 & \begin{tabular}{l|l}
0 &
\end{tabular} & \begin{tabular}{l|l}
0 &
\end{tabular} & 0 & 0 & 0 & 0 & 0 & 0 & 0 & 0 & 4 \\
\hline
\end{tabular}


Table 2: Summary of gender and race data for IBD patients and normal controls.

$\mathrm{F}=$ Female, $\mathrm{M}=$ Male, $\mathrm{A}=$ Asian, $\mathrm{AA}=\mathrm{African}$ American, $\mathrm{C}=$ Caucasian

\begin{tabular}{|c|c|c|c|c|}
\hline \multicolumn{5}{|c|}{ SUMMARY DATA FOR GENDER AND RACE } \\
\hline \multicolumn{5}{|c|}{ The FREQ Procedure } \\
\hline \multicolumn{5}{|c|}{ GROUP=IBD } \\
\hline \multirow[t]{2}{*}{ SEX } & Frequency & Percent & Cumulative & Cumulative \\
\hline & & & Frequency & Percent \\
\hline $\mathrm{F}$ & 54 & 54 & 54 & 54 \\
\hline M & 46 & 46 & 100 & 100 \\
\hline \multirow[t]{2}{*}{ RACE } & Frequency & Percent & Cumulative & Cumulative \\
\hline & & & Frequency & Percent \\
\hline A & 2 & 2 & 2 & 2 \\
\hline AA & 7 & 7 & 9 & 9 \\
\hline c & 91 & 91 & 100 & 100 \\
\hline & & & & \\
\hline & & & & \\
\hline \multicolumn{5}{|c|}{ SUMMARY DATA FOR GENDER AND RACE } \\
\hline \multirow{2}{*}{\multicolumn{5}{|c|}{ The FREQ Procedure }} \\
\hline & & & & \\
\hline \multicolumn{5}{|c|}{ GROUP=N } \\
\hline & & & & \\
\hline \multirow[t]{2}{*}{ SEX } & Frequency & Percent & Cumulative & Cumulative \\
\hline & & & Frequency & Percent \\
\hline $\mathrm{F}$ & 63 & 64 & 64 & 64 \\
\hline$M$ & 37 & 36 & 100 & 100 \\
\hline \multirow[t]{2}{*}{ RACE } & Frequency & Percent & Cumulative & Cumulative \\
\hline & & & Frequency & Percent \\
\hline A & 2 & 2 & 2 & 2 \\
\hline AA & 7 & 7 & 9 & 9 \\
\hline C & 91 & 91 & 100 & 100 \\
\hline
\end{tabular}


Table 3: Age distribution by decades of inflammatory bowel disease patients and normal controls.

$\mathrm{IBD}=$ inflammatory bowel disease, $\mathrm{N}=$ normal

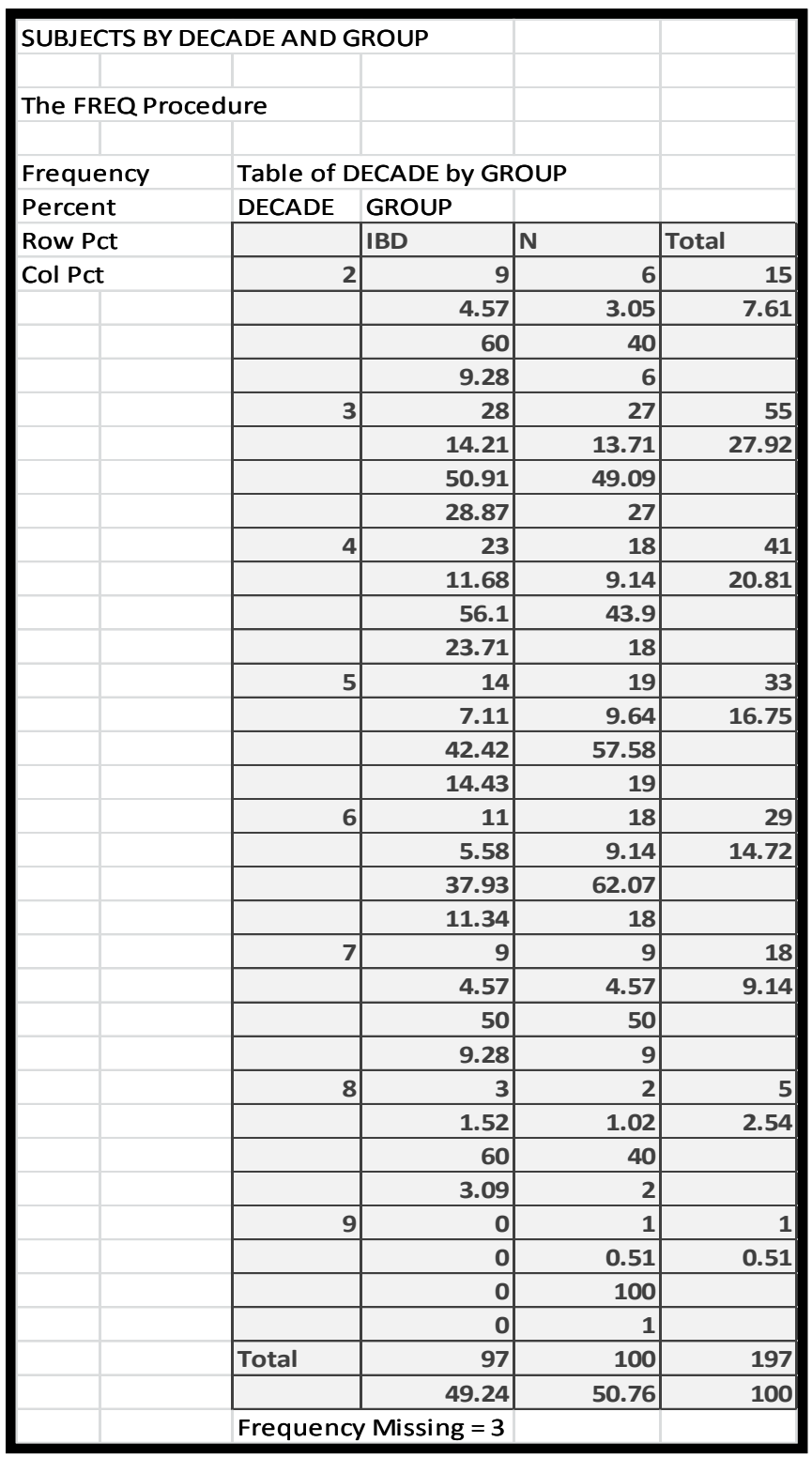




\section{Appendix B: Human Subject Research Forms}

CONSENT

Biomedical/Cancer
IRB Protocol Number: $2012 \mathrm{H} 0430$

IRB Approval date: Feb, 82013

Version: 1.0

The Ohio State University Consent to Participate in Research

Study Title:

Prevalence of Oral Lesions in Patients with Inflammatory Bowel Disease

Principal Investigator:

Dr. Carl M Allen

- This is a consent form for research participation. It contains important information about this study and what to expect if you decide to participate. Please consider the information carefully. Feel free to discuss the study with your friends and family and to ask questions before making your decision whether or not to participate.

- Your participation is voluntary. You may refuse to participate in this study. If you decide to take part in the study, you may leave the study at any time. No matter what decision you make, there will be no penalty to you and you will not lose any of your usual benefits. Your decision will not affect your future relationship with The Ohio State University. If you are a student or employee at Ohio State, your decision will not affect your grades or employment status.

- You may or may not benefit as a result of participating in this study. Also, as explained below, your participation may result in unintended or harmful effects for you that may be minor or may be serious depending on the nature of the research.

- You will be provided with any new information that develops during the study that may affect your decision whether or not to continue to participate. If you decide to participate, you will be asked to sign this form and will receive a copy of the form. You are being asked to consider participating in this study for the reasons explained below.

1. Why is this study being done?

Oral lesions (sores or abnormalities in the mouth) are not uncommon in patients with inflammatory bowel disease, and may occasionally be the first manifestations of disease. However, very little information is currently available about this problem. In this study, we want to determine the frequency and type of oral lesions that can be specifically linked to inflammatory bowel disease. Your participation in the study will allow us to collect this information

2. How many people will take part in this study?

A total of three hundred people will participate in this study, one hundred of which will have inflammatory bowel disease.

3. What will happen if I take part in this study?

After consenting to participate in this study, your medical history will be reviewed and you will undergo a standard comprehensive oral examination. The oral examination will consist of 
visual inspection of the teeth and the lining of your mouth in well lit conditions using an examination mirror. Written, and possibly photographic, documentation of any oral abnormalities will be recorded. The oral examination will be repeated at your 3, 6 and 9 month follow-up appointments, to identify any mucosal changes.

\section{How long will I be in the study?}

The study period is 9 months. You will be asked to return for a reevaluation at 3 month intervals, with evaluations lasting approximately 15 minutes each.

\section{Can I stop being in the study?}

You may leave the study at any time. If you decide to stop participating in the study, there will be no penalty to you, and you will not lose any benefits to which you are otherwise entitled. Your decision will not affect your future relationship with The Ohio State University.

\section{What risks, side effects or discomforts can I expect from being in the study?}

There are no direct risks, side effects or discomforts associated with an oral examination. However, there is the possibility of identification of previously undiagnosed oral disease.

\section{What benefits can I expect from being in the study?}

You will receive a comprehensive oral examination, which includes an oral cancer screening, at no charge. While this examination may not directly benefit you, it is expected that the results from this study will help clinicians to recognize and properly diagnose oral lesions associated with inflammatory bowel disease.

\section{What other choices do I have if I do not take part in the study?}

You may choose not to participate without penalty or loss of benefits to which you are otherwise entitled.

\section{Will my study-related information be kept confidential?}

Efforts will be made to keep your study-related information confidential. Digital information will be stored on restricted and password protected computers, managed by the Information Technology Services at The Ohio State University, College of Dentistry. Hard copies will be stored in locked file cabinets of a locked private office at The Ohio State University, College of Dentistry. Access to the information will be restricted to individuals directly involved with the study. However, there may be circumstances where this information must be released. For example, personal information regarding your participation in this study may be disclosed if required by state law.

Also, your records may be reviewed by the following groups (as applicable to the research):

- Office for Human Research Protections or other federal, state, or international regulatory agencies;

- U.S. Food and Drug Administration;

- The Ohio State University Institutional Review Board or Office of Responsible Research Practices; 
- The sponsor supporting the study, their agents or study monitors; and

- Your insurance company (if charges are billed to insurance).

If this study is related to your medical care, your study-related information may be placed in your permanent hospital, clinic, or physician's office records. Authorized Ohio State University staff not involved in the study may be aware that you are participating in a research study and have access to your information.

You may also be asked to sign a separate Health Insurance Portability and Accountability Act (HIPAA) research authorization form if the study involves the use of your protected health information.

10. What are the costs of taking part in this study?

There are no costs for participating in this study. You will be responsible for paying for parking.

11. Will I be paid for taking part in this study?

You will not be paid for participating in this study.

12. What happens if I am injured because I took part in this study?

If you suffer an injury from participating in this study, you should notify the researcher or study doctor immediately, who will determine if you should obtain medical treatment at The Ohio State University Medical Center.

The cost for this treatment will be billed to you or your medical or hospital insurance. The Ohio State University has no funds set aside for the payment of health care expenses for this study

\section{What are my rights if I take part in this study?}

If you choose to participate in the study, you may discontinue participation at any time without penalty or loss of benefits. By signing this form, you do not give up any personal legal rights you may have as a participant in this study.

You will be provided with any new information that develops during the course of the research that may affect your decision whether or not to continue participation in the study.

You may refuse to participate in this study without penalty or loss of benefits to which you are otherwise entitled.

An Institutional Review Board responsible for human subjects research at The Ohio State University reviewed this research project and found it to be acceptable, according to applicable state and federal regulations and University policies designed to protect the rights and welfare of participants in research. 
14. Who can answer my questions about the study?

For questions, concerns, or complaints about the study you may contact 614-247-4282.

For questions about your rights as a participant in this study or to discuss other study-related concerns or complaints with someone who is not part of the research team, you may contact Ms. Sandra Meadows in the Office of Responsible Research Practices at 1-800-678-6251.

If you are injured as a result of participating in this study or for questions about a study-related injury, you may contact Dr. Carl Allen 614-292-6577. 


\section{Signing the consent form}

I have read (or someone has read to $\mathrm{me}$ ) this form and I am aware that I am being asked to participate in a research study. I have had the opportunity to ask questions and have had them answered to my satisfaction. I voluntarily agree to participate in this study.

I am not giving up any legal rights by signing this form. I will be given a copy of this form.

Printed name of subject consent for subject (when applicable)

Relationship to the subject

\section{Signature of subject}

AM/PM

$$
\text { Date and time }
$$

\section{Signature of person authorized to consent} for subject

(when applicable)

AM/PM

Date and time

\section{Investigator/Research Staff}

I have explained the research to the participant or his/her representative before requesting the signature(s) above. There are no blanks in this document. A copy of this form has been given to the participant or his/her representative.

Printed name of person obtaining consent

\section{Signature of person obtaining consent AM/PM \\ Date and time}

Witness(es) - May be left blank if not required by the IRB

Printed name of witness Signature of witness 


$$
\square
$$


CONSENT

Biomedical/Cancer
IRB Protocol Number: $2012 \mathrm{H} 0340$ IRB Approval date: $02-06-2012$

Version: 1.0

The Ohio State University Consent to Participate in Research

Study Title:

Prevalence of Oral Lesions in Patients with Inflammatory Bowel Disease

Principal Investigator:

Dr. Carl M Allen

- This is a consent form for research participation. It contains important information about this study and what to expect if you decide to participate. Please consider the information carefully. Feel free to discuss the study with your friends and family and to ask questions before making your decision whether or not to participate.

- Your participation is voluntary. You may refuse to participate in this study. If you decide to take part in the study, you may leave the study at any time. No matter what decision you make, there will be no penalty to you and you will not lose any of your usual benefits. Your decision will not affect your future relationship with The Ohio State University. If you are a student or employee at Ohio State, your decision will not affect your grades or employment status.

- You may or may not benefit as a result of participating in this study. Also, as explained below, your participation may result in unintended or harmful effects for you that may be minor or may be serious depending on the nature of the research.

- You will be provided with any new information that develops during the study that may affect your decision whether or not to continue to participate. If you decide to participate, you will be asked to sign this form and will receive a copy of the form. You are being asked to consider participating in this study for the reasons explained below.

\section{Why is this study being done?}

Oral lesions (ie-sores or abnormalities in the mouth) are not uncommon in patients with inflammatory bowel disease, and may occasionally be the first manifestations of disease. However, very little information is currently available about this problem. In this study, we want to determine the frequency and type of oral lesions that can be specifically linked to inflammatory bowel disease. Your participation will allow us to exclude lesions seen in the general population to be linked with inflammatory bowel disease.

2. How many people will take part in this study?

A total of three hundred people will participate in this study, one hundred of which will healthy individuals seen routinely in the screening clinics.

3. What will happen if I take part in this study?

After consenting to participate in this study, your medical history will be reviewed and you will undergo a standard comprehensive oral examination, consisting of visual inspection of the lining of your mouth. Written, and possibly photographic, documentation of any oral abnormalities will be recorded.

4. How long will I be in the study?

You will undergo a single comprehensive oral examination, which should take no longer than 20 minutes. 
5. Can I stop being in the study?

You may leave the study at any time. If you decide to stop participating in the study, there will be no penalty to you, and you will not lose any benefits to which you are otherwise entitled. Your decision will not affect your future relationship with The Ohio State University.

6. What risks, side effects or discomforts can I expect from being in the study?

There are no direct risks, side effects or discomforts associated with an oral examination. However, there is the possibility of identification of previously undiagnosed oral disease.

\section{What benefits can I expect from being in the study?}

You will receive a comprehensive oral examination, which includes an oral cancer screening, at no charge. While this examination may not directly benefit you, it is expected that the results from this study will help clinicians to recognize and properly diagnose oral lesions associated with inflammatory bowel disease.

\section{What other choices do I have if I do not take part in the study?}

You may choose not to participate without penalty or loss of benefits to which you are otherwise entitled.

\section{Will my study-related information be kept confidential?}

Efforts will be made to keep your study-related information confidential. Digital information will be stored on restricted and password protected computers, managed by the Information Technology Services at The Ohio State University, College of Dentistry. Hard copies will be stored in locked file cabinets of a locked private office at The Ohio State University, College of Dentistry. Access to the information will be restricted to individuals directly involved with the study. However, there may be circumstances where this information must be released. For example, personal information regarding your participation in this study may be disclosed if required by state law

Also, your records may be reviewed by the following groups (as applicable to the research):

- $\quad$ Office for Human Research Protections or other federal, state, or international regulatory agencies:

- U.S. Food and Drug Administration;

- The Ohio State University Institutional Review Board or Office of Responsible Research Practices;

- The sponsor supporting the study, their agents or study monitors; and

- Your insurance company (if charges are billed to insurance).

If this study is related to your medical care, your study-related information may be placed in your permanent hospital, clinic, or physician's office records. Authorized Ohio State University staff not involved in the study may be aware that you are participating in a research study and have access to your information.

A description of this clinical trial will be available on http://www.ClinicalTrials.gov, as required by U.S. law. This website will not include information that can identify you. At most, the website will include a summary of the results. You can search the website at any time.

You may also be asked to sign a separate Health Insurance Portability and Accountability Act (HIPAA) research authorization form if the study involves the use of your protected health information. 
10. What are the costs of taking part in this study?

There are no costs for participating in this study. You will be responsible for paying for parking

11. Will I be paid for taking part in this study?

You will not be paid for participating in the study.

12. What happens if I am injured because I took part in this study?

If you suffer an injury from participating in this study, you should notify the researcher or study doctor immediately, who will determine if you should obtain medical treatment at The Ohio State University Medical Center.

The cost for this treatment will be billed to you or your medical or hospital insurance. The Ohio State University has no funds set aside for the payment of health care expenses for this study

\section{What are my rights if I take part in this study?}

If you choose to participate in the study, you may discontinue participation at any time without penalty or loss of benefits. By signing this form, you do not give up any personal legal rights you may have as a participant in this study.

You will be provided with any new information that develops during the course of the research that may affect your decision whether or not to continue participation in the study.

You may refuse to participate in this study without penalty or loss of benefits to which you are otherwise entitled.

An Institutional Review Board responsible for human subjects research at The Ohio State University reviewed this research project and found it to be acceptable, according to applicable state and federal regulations and University policies designed to protect the rights and welfare of participants in research.

\section{Who can answer my questions about the study?}

For questions, concerns, or complaints about the study you may contact Dr. Carl Allen DDS, MSD at 614-2926577.

For questions about your rights as a participant in this study or to discuss other study-related concerns or complaints with someone who is not part of the research team, you may contact Ms. Sandra Meadows in the Office of Responsible Research Practices at 1-800-678-6251.

If you are injured as a result of participating in this study or for questions about a study-related injury, you may contact Dr. Carl Allen DDS, MSD at 614-292-6577. 


\section{Signing the consent form}

I have read (or someone has read to $\mathrm{me}$ ) this form and I am aware that I am being asked to participate in a research study. I have had the opportunity to ask questions and have had them answered to my satisfaction. I voluntarily agree to participate in this study.

I am not giving up any legal rights by signing this form. I will be given a copy of this form.

Printed name of subject consent for subject (when applicable)

Relationship to the subject

\section{Signature of subject}

AM/PM

$$
\text { Date and time }
$$

\section{Signature of person authorized to consent} for subject

(when applicable)

AM/PM

Date and time

\section{Investigator/Research Staff}

I have explained the research to the participant or his/her representative before requesting the signature(s) above. There are no blanks in this document. A copy of this form has been given to the participant or his/her representative.

\section{Printed name of person obtaining consent}

Signature of person obtaining consent

Date and time

Witness(es) - May be left blank if not required by the IRB
Signature of witness 


$$
\square
$$


THE OHIO STATE UNIVERSITY

AUTHORIZATION TO USE

PERSONAL HEALTH INFORMATION IN RESEARCH

Title of the Study: Prevalence of Oral Lesions in Patients with Inflammatory Bowel Disease

Protocol Number:

Principal Investigator: Dr. Carl M Allen

\section{Subject Name}

Before researchers use or share any health information about you as part of this study, The Ohio State University is required to obtain your authorization. This helps explain to you how this information will be used or shared with others involved in the study.

- The Ohio State University and its hospitals, clinics, health-care providers, and researchers are required to protect the privacy of your health information.

- You should have received a Notice of Privacy Practices when you received health care services here. If not, let us know and a copy will be given to you. Please carefully review this information. Ask if you have any questions or do not understand any parts of this notice.

- If you agree to take part in this study your health information will be used and shared with others involved in this study. Also, any new health information about you that comes from tests or other parts of this study will be shared with those involved in this study.

- Health information about you that will be used or shared with others involved in this study may include your research record and any health care records at The Ohio State University. For example, this may include your medical records, $x$-rays, or laboratory results. Psychotherapy notes in your health records (if any) will not, however, be shared or used. Use of these notes requires a separate, signed authorization.

Please read the information carefully before signing this form. Please ask if you have any questions about this authorization, the university's Notice of Privacy Practices or the study before signing this form.

\section{Those Who May Use, Share, and Receive Your Information as Part of This Study}

- Researchers and staff at The Ohio State University will use, share, and receive your personal health information for this research study. Authorized Ohio State staff not involved in the study may be aware that you are participating in a research study and have access to your information. If this study is related to your medical care, your study-related information may be placed in your permanent hospital, clinic, or physician's office records.

Initials/Date: 
- Those who oversee the study will have access to your information, including the following:

- Members and staff of The Ohio State University's Institutional Review Boards, including the Western Institutional Review Board

- The Ohio State University Office of Responsible Research Practices

- University data safety monitoring committees

- The Ohio State University Office of Research.

- Your health information may also be shared with federal and state agencies that have oversight of the study or to whom access is required under the law. These may include the following:

- Food and Drug Administration

- Office for Human Research Protections

- National Institutes of Health

- Ohio Department of Job and Family Services.

The information that is shared with those listed above may no longer be protected by federal privacy rules.

\section{Authorization Period}

This authorization will not expire unless you change your mind and revoke it in writing. There is no set date at which your information will be destroyed or no longer used. This is because the information used and created during the study may be analyzed for many years, and it is not possible to know when this will be completed.

Initials/Date

\section{Signing the Authorization}

- You have the right to refuse to sign this authorization. Your health care outside of the study, payment for your health care, and your health care benefits will not be affected if you choose not to sign this form.

- You will not be able to take part in this study and will not receive any study treatments if you do not sign this form.

- If you sign this authorization, you may change your mind at any time. Researchers may continue to use information collected up until the time that you formally changed your mind. If you change your mind, your authorization must be revoked in writing. To revoke your authorization, please write to: Dr. Carl M Allen, 2194 Postle Hall, 305W 12 ${ }^{\text {th }}$ Avenue, Columbus, OH 43201, (614)-292-6577.

- Signing this authorization also means that you will not be able to see or copy your study-related information until the study is completed. This includes any portion of your medical records that describes study treatment.

\section{Contacts for Questions}

- If you have any questions relating to your privacy rights, please contact: Manju E Oommen, 1130 Postle Hall, $305 \mathrm{~W}, 12^{\text {th }}$ Avenue, Columbus, $\mathrm{OH} 43201$.

- If you have any questions relating to the research, please contact: Dr. Carl M Allen, (614)-292-6577.

Page 2 of 3

$03 / 16 / 12$ 


\section{Signature}

I have read (or someone has read to me) this form and have been able to ask questions. All of my questions about this form have been answered to my satisfaction. By signing below, I permit Dr. Carl M Allen and the others listed on this form to use and share my personal health information for this study. I will be given a copy of this signed form.

Signature

(Subject or Legally Authorized Representative)

Print Name Date Time AM/PM

(If legal representative, also print relationship to subject) 


\section{Appendix C: Data Collection Forms}

PREVALENCE OF ORAL LESIONS IN PATIENTS WITH IBD

\section{DATA COLLECTION SHEET}

Subject no.

Name:

Age:

Race:

Gender:

Group:

Diagnosis:

Date:

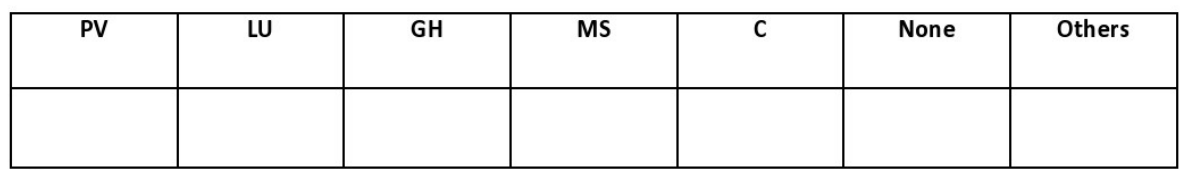

Note:

Date:

\begin{tabular}{|c|c|c|c|c|c|c|}
\hline PV & LU & GH & MS & C & None & Others \\
\hline & & & & & & \\
\hline
\end{tabular}

Note:

Date:

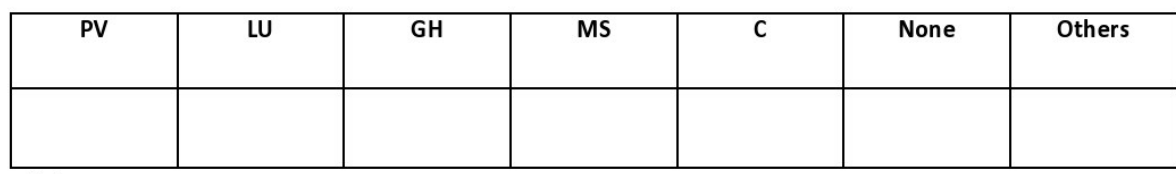

Note:

Date:

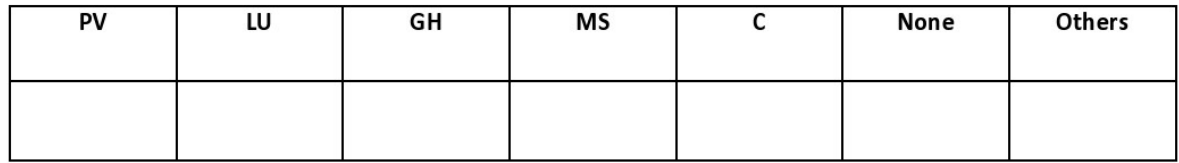

Note:

PV: Pyostomatitis Vegetans

LU: Linear ulceration

GH: Gingival hyperplasia MS: Mucosal swelling

C: Cobblestone appearance

B: Buccal mucosa $\quad$ L: Labial mucosa P: Palatal mucosa

Li: Lingual mucosa

G: Gingival mucosa 


\section{PREVALENCE OF ORAL LESIONS IN PATIENTS WITH IBD}

\section{DATA COLLECTION SHEET}

Age:

Group:
Race:

Diagnosis:

Date:

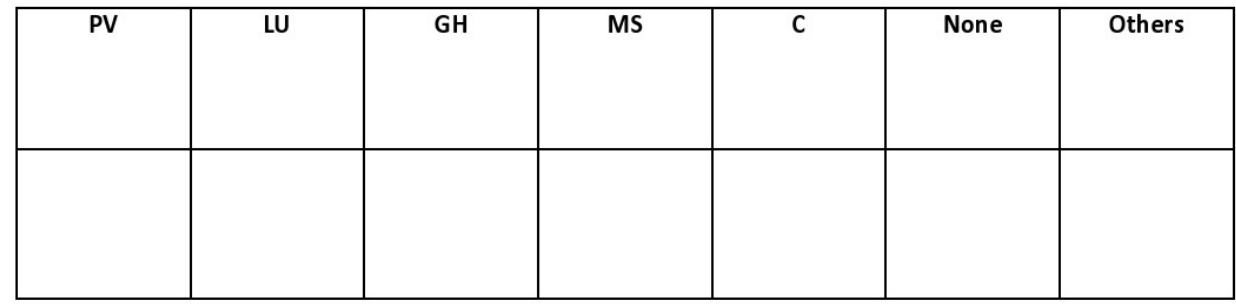

PV: Pyostomatitis Vegetans

LU: Linear ulceration

GH: Gingival hyperplasia MS: Mucosal swelling

C: Cobblestone appearance

B: Buccal mucosa

L: Labial mucosa

P: Palatal mucosa

Li: Lingual mucosa

G: Gingival mucosa 